${ }^{\star}$ Graphi|cal Abstract (for review)

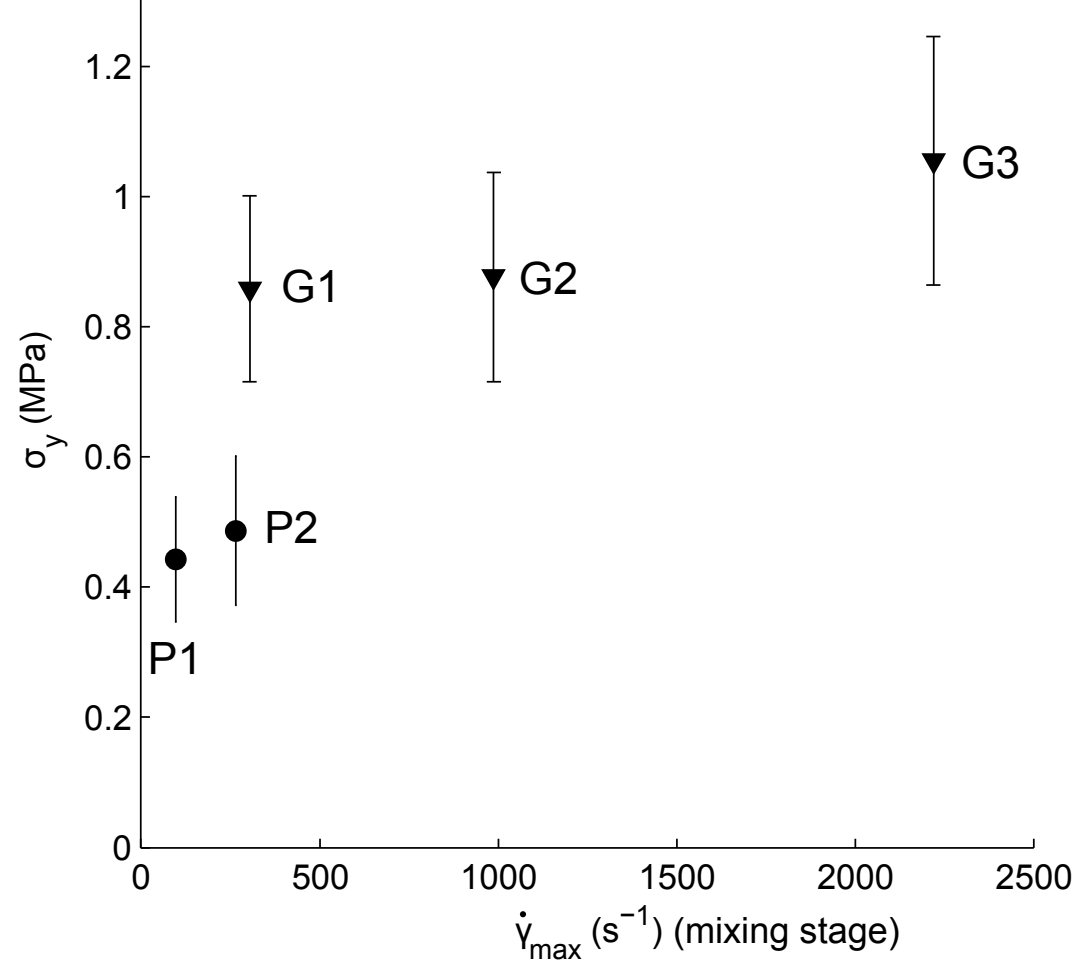




\title{
1. The effect of mixing on the extrusion-spheronisation of a micro-crystalline cellulose paste
}

\author{
M. P. Bryan, M. D. Kent, J. Rickenbach, G. Rimmer, D. I. Wilson, \\ S. L. Rough* \\ Department of Chemical Engineering and Biotechnology, University of Cambridge, \\ Pembroke Street, Cambridge, CB2 3RA, UK
}

Keywords: micro-crystalline cellulose, extrusion, spheronisation, mixing, pharmaceutical paste, Benbow-Bridgwater

\begin{abstract}
The effect of mixer shear strain rate on the performance of a model micro-crystalline cellulose pharmaceutical paste undergoing extrusion-spheronisation was studied using a laboratory scale planetary mixer and a screw-based mixer. The maximum shear strain rate in each mixer was estimated. Five pastes were prepared, one each at 97 and $265 \mathrm{~s}^{-1}$ in the planetary mixer, and one each at 304, 988 and $2220 \mathrm{~s}^{-1}$ in the screw mixer. The rheology of the pastes was quantified by Benbow-Bridgwater characterisation based on ram extrusion. Each paste was spheronised and pellet size and shape distributions obtained by automated size analysis. Mixer type (rather than shear strain rate) was found to have the strongest influence on the paste properties, with the screw-mixed material having a higher yield strength and forming smaller pellets with a narrower size distribution when spheronised under identical conditions.
\end{abstract}

\section{Introduction}

Micro-crystalline cellulose (MCC) is a wood pulp derived bio-polymer used as an excipient in pharmaceutical tablet and capsule production. Its water re-

Prëprint submitted to Elsevier

December 11, 2014

Corresponding author, slr1002@cam.ac.uk, +44(0)1223 334772 
tention characteristics and excellent bio-compatibility have led to its acceptance as a 'gold standard' material, both industrially and in tabletting research in the laboratory [1].

One method by which MCC is processed in the pharmaceutical sector is extrusion-spheronisation $(\mathrm{E}-\mathrm{S})$. $\mathrm{E}-\mathrm{S}$ can be used to form dense pellets with controlled, high sphericity [2], which are desirable in tablet and capsule manufacture due to their easily characterised (and controlled) dose profile and good flow characteristics. As the name implies, E-S is a two-stage operation: a softsolid material is prepared by mixing of the excipient, the desired active pharmaceutical ingredients (APIs) and liquid binders, which is extruded to form rods of a specific diameter; these rods are then spheronised to form round, dense pellets which are then dried or otherwise processed further [3, 4].

Extrusion is a unit operation in which a material (in this context a stiff paste) is shaped by flow in a primarily extensional mode through a contraction (termed a die). The process relies on the paste being able to retain its shape on exiting the extruder, a property closely related to its plastic yield strength. Vervaet et al. [3] noted that there is a broad range of extrusion devices used for pharmaceutical manufacture including roller- and swept-screen extruders, screw-driven extruders and (particularly at the laboratory scale) ram extruders. These devices differ primarily in their throughput, with continuous processing screen-type extruders possessing a large die-flow area, whereas batch-operated ram extruders typically have one small orifice for the entire product stream.

Spheronisation (or marumerisation) is a process by which the product of extrusion (termed extrudate) can be rounded through collision, the energy for deformation being supplied by a rotating serrated plate. This requires the constituent paste to have a yield strength $\left(\sigma_{\mathrm{y}}\right)$ that is low enough to permit deformation, but high enough for the final pellets to retain their shape. This balance manifests in the dimensionless groups:

$$
\frac{\sigma_{\mathrm{y}}}{\rho g L_{\mathrm{p}}} \quad \text { and } \quad \frac{\rho U_{\mathrm{c}}^{2}}{\sigma_{\mathrm{y}}}
$$

representing the tendency to deform under self weight, and the tendency to 
deform during a collision, respectively (for pellet density $\rho$, gravitational acceleration $g$, pellet size $L_{\mathrm{p}}$ and collision speed $U_{\mathrm{c}}$ ). The yield stress, $\sigma_{\mathrm{y}}$, appears in both groups and is hence critical to the spheronisation performance of a given material.

This balance is further complicated by the fracture and cohesive properties of the paste, which must prevent breakage to a powder state or agglomeration into a single mass [5]. These properties, including the yield strength, are largely governed by the formulation of the material and are particularly sensitive to the liquid to solids ratio.

One aspect of $\mathrm{E}-\mathrm{S}$ that is often overlooked is the mixing stage (sometimes termed wet granulation), in which the stiff paste is formed from dry powder and a binder liquid before extrusion. The granulation stage can be carried out in a variety of devices including planetary, rotary Z- and sigma-blade mixers or auger driven mixer/kneaders, each with its own set of advantages and disadvantages of throughput and scale-up [3].

All of these devices mix through the application of strain to the heterogeneous wet powder mass. Rotary blade mixers act primarily through shear strain, repeatedly cutting and scraping the paste against the enclosure walls. An auger driven kneader, by contrast, operates through a complex combination of shear and extensional strain, as the material is conveyed along the mixing channel, being repeatedly compressed and broken apart.

The effect of strain and strain rate history on the properties of pastes is largely unquantified, and the influence of the mixing stage on both the extrusion and spheronisation behaviour is poorly understood. This is largely due to the inherent difficulties in estimating the strain history of a conventionally mixed material, and the fact that most studies of $\mathrm{E}-\mathrm{S}$ behaviour only use one type of mixer and mixing protocol.

One study of the effect of the granulation stage on E-S is that of Schmidt and Kleinebudde [6]. They studied the effect of three types of mixer, a planetary, high shear and twin screw granulator, on the spheronisation performance and pellet properties for an MCC/paracetamol/water paste. They found that the 
mixer type affected a range of product properties including pellet aspect ratio, dry pellet crushing strength and the paracetamol dissolution profile, but they did not report their observations of the extrusion behaviour in detail.

Vervaet and Remon [7], in contrast, concluded that the mixing time, liquid addition rate and mixer speed had no influence on the extrusion behaviour or final pellet size and shape distributions for MCC pastes incorporating Avicel PH101 and RC581, with or without a model drug compound.

Continuous granulators, particularly varieties of screw extruders, have also been studied with regard to their effect on granule properties. Djuric et al. [8] compared two twin-screw extruders from different manufacturers to test the effects of material input rate and screw rotation rate, using dicalcium phosphate and lactose. Without studying the E-S behaviour of the granules produced, they observed differences in granule friability, flowability and tendency to form fines, and concluded that mixer-extruders are not interchangeable even when operated under similar conditions. Djuric and Kleinebudde [9] carried out a similar study using one twin-screw extruder with adjustable mixing and kneading elements, concluding also that the mixing stage influences a variety of granule properties.

These results suggest that data from academic studies of E-S may not necessarily be comparable if the mixing method and conditions are not consistent, even if aspects such as the liquid/solid ratio or constituent powder particle sizes are constant (which is unlikely). This is exacerbated in an industrial context during process development. Formulations are developed at the lab-scale, using one type of mixer, whereas a different type of mixer is often employed for manufacture. Considerable time and other resources could be expended in modifying protocols for manufacture. Identifying key factors that affect the $\mathrm{E}-\mathrm{S}$ behaviour is thus an important undertaking in formulation design.

We aim to present results adding to the work of Schmidt and Kleinebudde [6] showing the effect of estimated maximum shear strain rate during the mixing stage on the E-S behaviour of a model MCC/water paste. Our study differs from [6] in that the liquid-solids ratio of our materials remains constant throughout (independent of the mixing method), removing a source of variation in the paste 
properties.

We have not taken into account the entire strain histories of the pastes studied as it is not practical to perform such calculations for a real mixer. We do, however, accept that parameters such as total strain or average strain rate may govern the system behaviour; we use the maximum shear strain rate as a proxy for these in the first instance.

\section{Materials and methods}

\subsection{Mixing}

\subsubsection{Protocols}

The stiff paste formulation used here was that employed by Zhang et al. [10], and consisted of MCC (Avicel PH101, FMC Corporation, Ireland) and reverse osmosis water mixed to a solids weight fraction of $45 \%$. The paste has previously been found to behave reproducibly in both square-entry ram extrusion and screen extrusion [11].

Five different mixing protocols were devised creating five pastes exposed to maximum shear strain rates $\left(\dot{\gamma}_{\max }\right)$ estimated in the range 97 to $2220 \mathrm{~s}^{-1}$, summarised in table 1 . The two pieces of mixing apparatus used were a planetary mixer (Kenwood Chef KM200, 1a) and a miniature-screw extruder (Food Grinder AT950B, figure 2a), both Kenwood Ltd, UK. The methods for estimation of $\dot{\gamma}_{\max }$ in both the planetary mixer and the grinder are found in the next section (2.1.2).

The planetary mixer operates via speed-controlled rotation of a flat, approximately semicircular beater about two axes, a central orbital axis and a secondary 'planetary' axis. These two rotations introduce a well-defined but complex path of the agitator blade through the material in the bowl.

The grinder uses the action of a rotating auger of length $10 \mathrm{~cm}$ to convey material (introduced manually at a steady rate) towards a perforated plate. The material is forced through the perforations by a cross-shaped blade in contact with the plate, which rotates with the auger. 
Table 1: Mixing protocols to achieve desired $\dot{\gamma}_{\max },(-)$ indicates that the material was not passed through the grinder

\begin{tabular}{lllll}
\hline Protocol & $\begin{array}{l}\text { Planetary mixing } \\
60 \mathrm{~s} \text { at speed 0 then: }\end{array}$ & $\begin{array}{l}\text { Grinder } \\
\text { speed }(\mathrm{rpm})\end{array}$ & $\begin{array}{l}\text { Grinder gap } \\
\text { size } b(\mathrm{~mm})\end{array}$ & $\begin{array}{l}\text { Estimated } \\
\dot{\gamma}_{\max }\left(\mathrm{s}^{-1}\right)\end{array}$ \\
\hline P1 & 600 s at speed 1 & $(-)$ & $(-)$ & 97 \\
P2 & & $(-)$ & $(-)$ & 265 \\
G1 & $120 \mathrm{~s}$ at speed 1 \\
G2 & 180 s at speed 2 & 65 & 1.5 & 304 \\
G3 & $120 \mathrm{~s}$ at speed 3 & 90 & 0.5 & 988 \\
90 & 0 & 2220 \\
\hline
\end{tabular}

Two planetary mixing protocols were used, a low shear strain protocol (labelled P1) to obtain as low a $\dot{\gamma}_{\max }$ as possible, and a higher shear strain protocol (P2) identical to that used by Zhang et al. [10]. Both P1 and P2 were specified to have the same overall mixing time (11 minutes).

The three remaining protocols utilised the grinder device, varying both the auger speed and the gap between the perforated plate and the rotating blade to adjust $\dot{\gamma}_{\max }$. These three pastes (G1, G2 and G3 in order of increasing $\dot{\gamma}_{\max }$ ) were initially mixed as paste $\mathrm{P} 2$ then subjected to further mixing in the grinder.

After mixing, each paste was stored in sealed containers for a period of four hours to allow the liquid phase to equilibrate within the MCC matrix. All paste was used within 8 hours of mixing and discarded after this time to minimise the effect of moisture loss. The standard mixing batch size was $500 \mathrm{~g}$ (liquid and solid phase together).

\subsubsection{Estimation of maximum shear strain rate}

The method of Chesterton et al. [12] was used to estimate the planetary mixer shear strain rate, with the geometry updated to that of the mixer used in the present work. The gap $a$ between the tangents (see figure 1b) of the beater and bowl was mapped as a function of vertical height from the bottom of the bowl, and the two rotations of the beater summed to provide a local linear velocity $u$ within the level of material fill. The shear strain rate was then estimated from $u / a$, and the maximum value at that rotation speed used to characterise the mixer. 


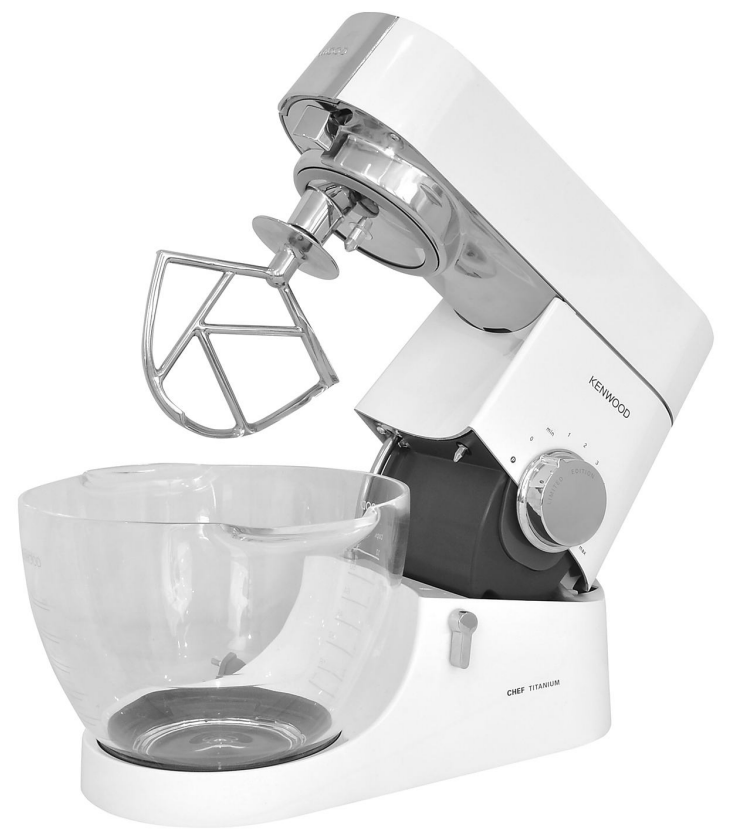

(a)

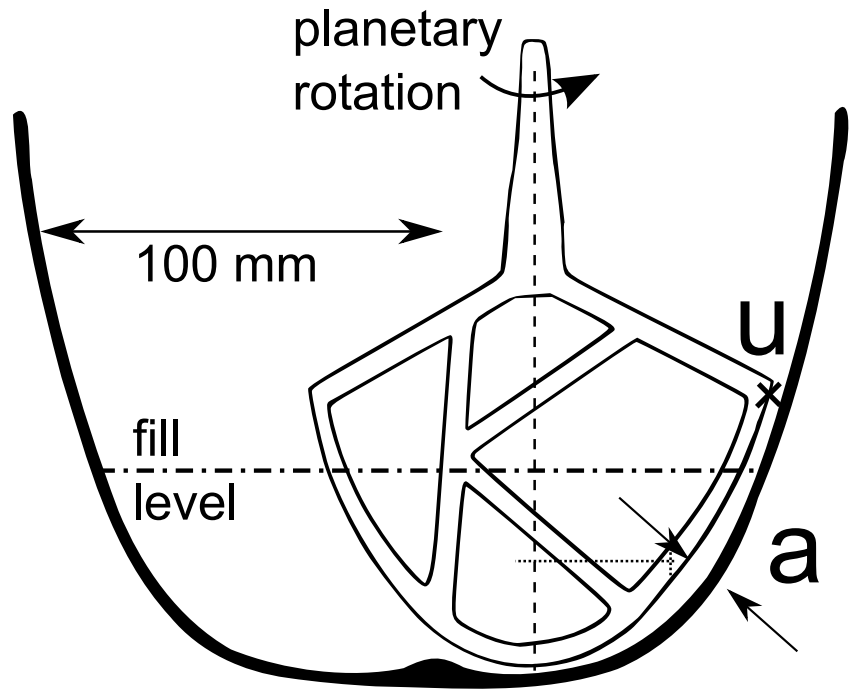

(b)

Figure 1: (a)Photograph of Kenwood Chef planetary mixer with ' $K$ ' beater attachment. [Source: kenwoodworld.com]. (b) Diagram of the ' $\mathrm{K}$ ' beater relative to the planetary mixer bowl, gap $a$ used for maximum shear strain rate estimation, with the beater tangential velocity $u$ calculated perpendicular to the page. Dashed line indicates the vertical planetary axis of the beater.

This analysis assumes that the paste experiences shear in the manner of a liquid within the gap. This assumption, while clearly far from the real behaviour, serves as a first estimate of the maximum shear strain rate. A better estimate of $\dot{\gamma}_{\max }$ would require detailed modelling of paste-bowl and paste-beater interactions, which lies outside the scope of the current work.

The grinder is more complex to analyse, as the flow field of the material being mixed is convoluted. It was assumed that the point of maximum shear strain rate occurs between the grinder end plate and the blade which scrapes material across it, at the greatest distance from the axis of rotation. This again allowed a similar estimate of the shear strain rate, viz. $v / b$, via measurement of the rotational speed of the auger and the gap size (see figure $2 \mathrm{~b}$ ). $\dot{\gamma}_{\max }$ could then be varied by adjusting either of these parameters. 


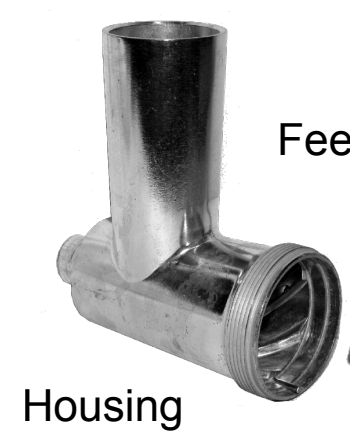

Housing
Feeder

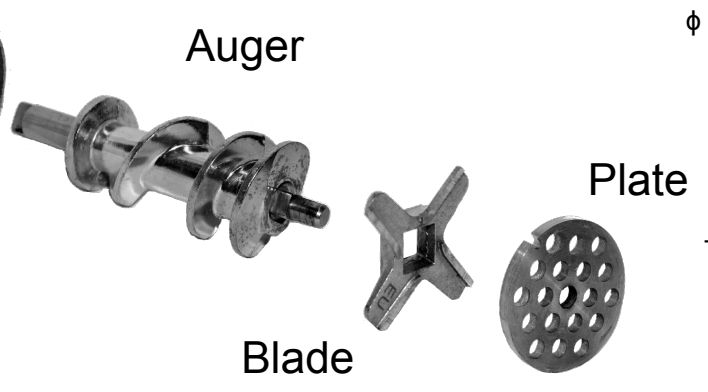

(a)

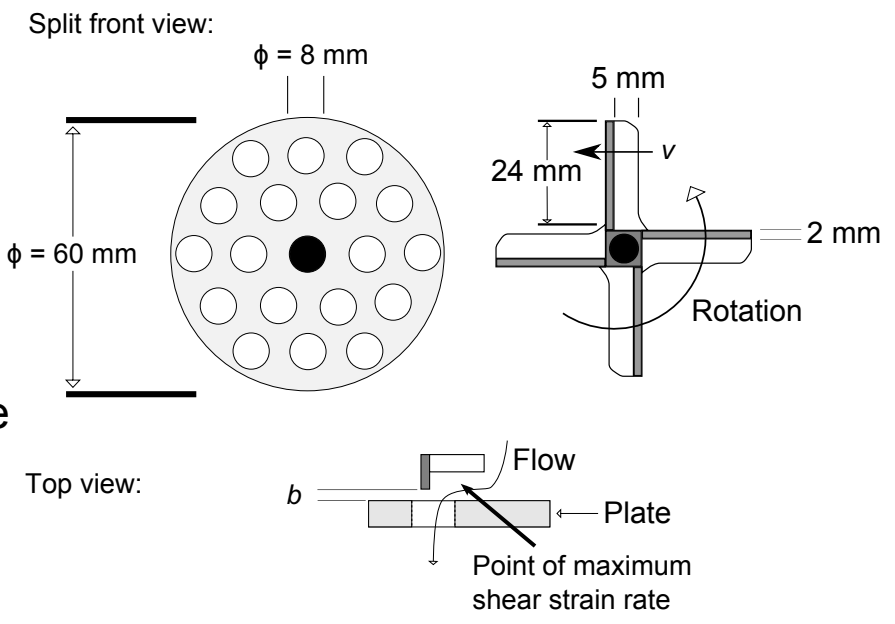

(b)

Figure 2: (a) Expanded view of Kenwood Food Grinder AT950B. (b) Schematic diagram of the Food Grinder end plate and blade: $b$ is the adjustable blade-plate clearance, $v$ is the linear velocity of the blade passing the outermost hole in the plate.

It is possible that there are positions between the auger and the grinder housing where the paste could experience higher maximum shear strain rates than those given by $v / b$. It was decided, however, that since all of the exiting paste must pass between the blade and the plate, whereas only a small portion of it may ever enter the gap between the auger and housing, that the estimate of $v / b$ was a more meaningful representation of the highest shear strain rate experienced by the extruded material.

\subsection{Paste characterisation}

Ram extrusion tests were performed using a Zwick-Roell Z050 computercontrolled strain frame (Zwick GmbH \& Co., Ulm, Germany) modified to operate as a vertical ram extruder, shown diagrammatically in figure 3a. Material confined in a cylindrical barrel is made to flow under the action of a moving ram through a single- or multi-holed die.

The strain frame allows the ram velocity to be controlled while recording the force on the ram face. This force is typically converted into an extrusion pressure $\left(P_{\mathrm{ex}}\right)$ based on barrel cross-sectional area. In all tests, the paste loaded into the 


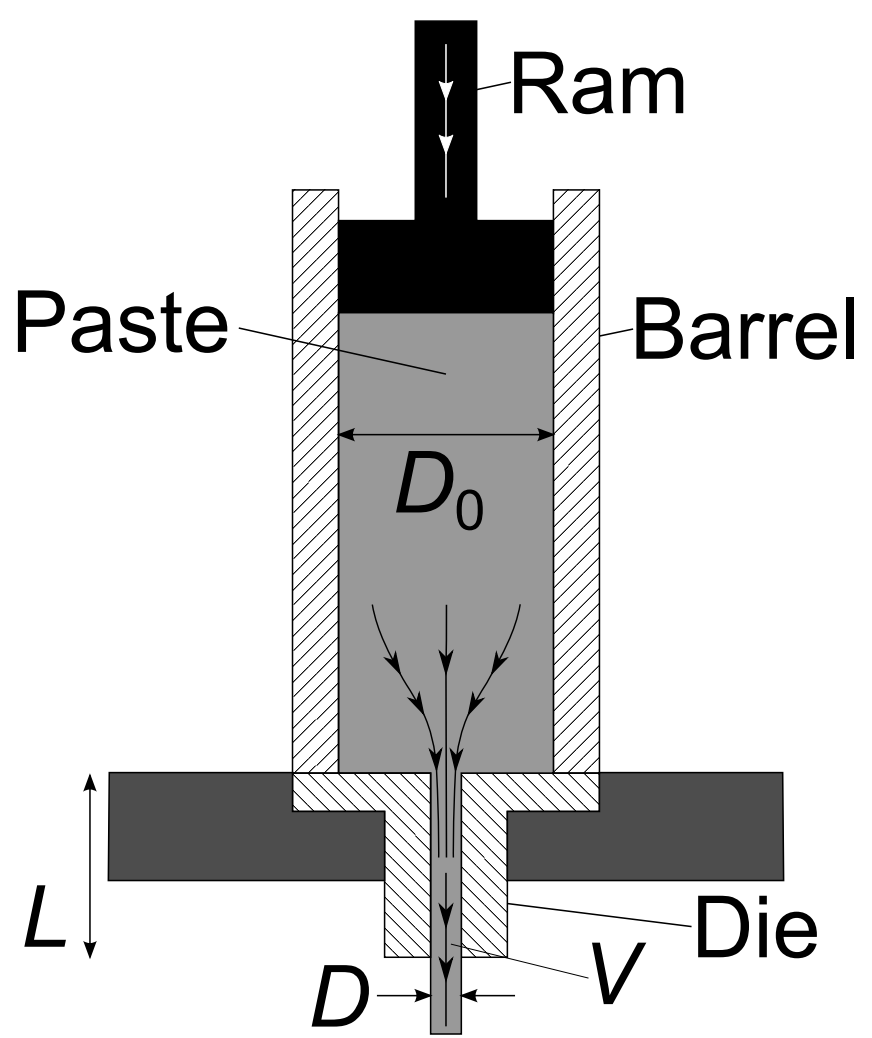

(a)
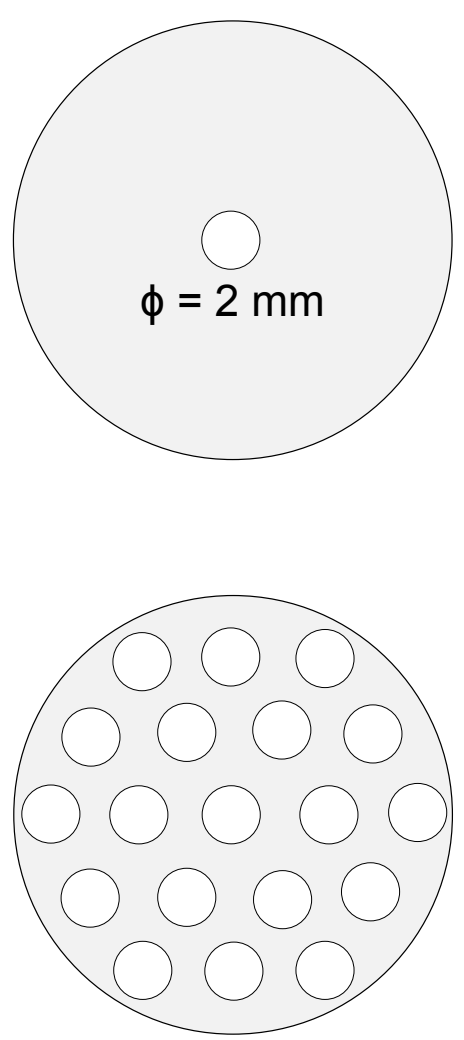

(b)

Figure 3: (a) Schematic diagram of the ram extrusion apparatus fitted with a single-holed die. (b) Plan views of the of the single- and multi-holed extrusion dies, with $D=2 \mathrm{~mm}$, not to scale.

barrel was compacted to a pressure of $1 \mathrm{MPa}$ before extrusion to minimise airfilled voids introduced during the barrel filling process.

The ram extrusion model of Benbow and Bridgwater [13] (BB) is a semianalytical model which decomposes the extrusion pressure into two components: the homogeneous work required to deform the paste between the pre- and postextrusion cross sections $\left(P_{1}\right)$, and the effect of shear stress experienced by the paste passing along the die land $\left(P_{2}\right)$. The extrusion pressure can vary in the first instance with the geometry of the extruder, specifically the barrel diameter 
$\left(D_{0}\right)$, the die diameter $(D)$ and the die land length $(L)$ :

$$
\begin{aligned}
P_{\mathrm{ex}} & =P_{1}+P_{2} \\
& =2 \sigma_{\mathrm{y}} \ln \frac{D_{0}}{D}+4 \tau_{\mathrm{w}} \frac{L}{D} \\
& =2\left(\sigma_{0}+\alpha V^{m}\right) \ln \frac{D_{0}}{D}+4\left(\tau_{0}+\beta V^{n}\right) \frac{L}{D}
\end{aligned}
$$

The model (equation 2) relies on two pseudo-properties of the materialextruder system: the yield stress $\sigma_{\mathrm{y}}$, which is a function of the characteristic extrusion velocity $(V)$ measured in the die land, and the wall shear stress $\tau_{\mathrm{w}}$, similarly a function of $V$. The parameters $\sigma_{\mathrm{y}}$ and $\tau_{\mathrm{w}}$ are typically expanded as in equation 2 to $\sigma_{0}+\alpha V^{m}$ and $\tau_{0}+\beta V^{n}$, respectively, to reflect this dependence on $V . \sigma_{0}$ and $\tau_{0}$ in this case represent a hypothetical yield stress and wall shear stress at zero velocity, whereas the remaining parameters describe the velocity dependence.

By performing a series of experiments using a sequence of single-holed dies with constant diameter $(D)$ but varying length $(L)$ it is possible to decouple $P_{1}$ and $P_{2}$, and in doing so extract the pseudo-properties $\sigma_{\mathrm{y}}$ and $\tau_{\mathrm{w}}$. Through the addition of extrusions at different velocities, the parameters $\sigma_{0}, \alpha, m ; \tau_{0}, \beta$ and $n$ can also be determined.

In the characterisation presented here, a cylindrical $11 \mathrm{~mm}$ diameter barrel was used with a series of concentric single-holed $2 \mathrm{~mm}$ diameter dies of length 2, 8, 12 and $24 \mathrm{~mm}$. Both the barrel and dies were constructed from machined stainless steel, and the extrusions were driven using a polyether ether ketone (PEEK) tipped steel rod as a ram. As the extruder is only able to control the ram velocity, rather than the extrudate velocity $(V)$, it was assumed that the paste was incompressible and in plug flow in the die land, such that the values of $V$ attained were 25, 50, 110, 180 and $250 \mathrm{~mm} / \mathrm{s}$.

\subsection{Spheronisation}

Spheronisation tests were carried out using paste extrudates generated by a modified extrusion protocol, employing a $25 \mathrm{~mm}$ diameter cylindrical barrel and a 19-hole $\times 2 \mathrm{~mm}$ diameter die as in figure $3 \mathrm{~b}$, with length $8 \mathrm{~mm}$ and with $V=$ 
$8.2 \mathrm{~mm} / \mathrm{s}$. $V$ was estimated assuming uniform flow through all orifices, which has been shown by Rahman et al. [14] to be a naive approximation. However, since the apparent shear strain rate in the die land for this flow (assuming Newtonian rheology) is of the order of $30 \mathrm{~s}^{-1}$, which is lower than $\dot{\gamma}_{\max }$ for the lowest shear paste P1 by a factor of three, it was decided that the potential fluctuation in velocity was not a cause for concern. Moreover, the same extrusion protocol was used for all pastes, such that any differences in the final spheronisation behaviour could only stem from the mixing stage.

The use of a multi-holed die was necessary so as to create a larger mass of extrudate than the single-holed characterisation extrusions, while not deviating substantially from the extrusion pressures encountered during the characterisation. The larger mass of extrudate was required to allow statistically significant spheronisation trials to be conducted.

Batch spheronisation was carried out using a Caleva Spheroniser 120 (Caleva Process Solutions Ltd, UK) fitted with a $120 \mathrm{~mm}$ diameter friction plate. The plate surface consisted of a square array of adjacent truncated square pyramids of height $0.86 \mathrm{~mm}$ and centre-centre separations of $1.40 \mathrm{~mm}$; the slope angle was 62.3 degrees relative to the horizontal, and the square truncated top had a side length $0.25 \mathrm{~mm}$. The mass of extrudates used for each spheronisation was $55 \mathrm{~g}$, and the friction plate rotational speed was $1600 \mathrm{rpm}$. The spheronisation times used were 1, 4 and 8 minutes so as to follow the time evolution of the pellet size and shape distributions. The spheronisation tests were carried out under ambient conditions (approximately $22^{\circ} \mathrm{C}$ ), with the temperature inside the spheroniser bowl not exceeding $25^{\circ} \mathrm{C}$ during any test.

After spheronisation, the pellets were dried in an oven at $40^{\circ} \mathrm{C}$ under vacuum at 0.8 bar(a) for a period of 48 hours. The water content of each batch of spheronised material was also recorded and compared to the water content of the freshly mixed and freshly extruded paste, to ensure that paste formulation was not an influencing factor on the $\mathrm{E}-\mathrm{S}$ behaviour. There was some loss of moisture but this was similar for all five pastes, with the final, post-spheronisation water content being in the range $52.5-53.5 \mathrm{wt} \%$ ( $c f .55 \mathrm{wt} \%$ just after mixing). 


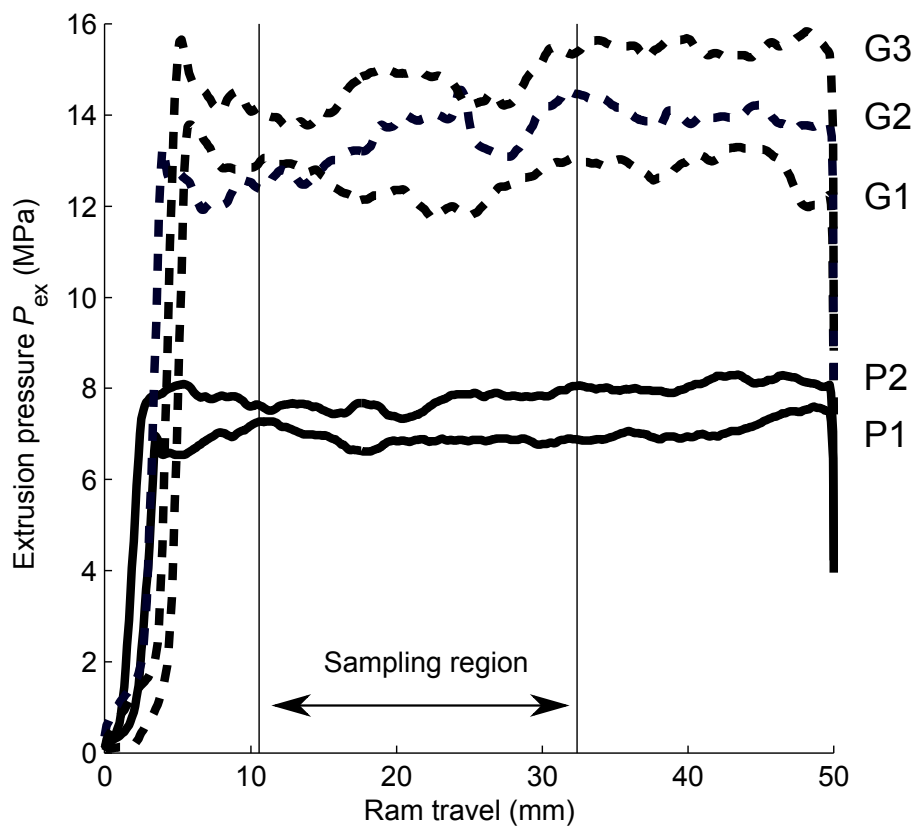

(a)

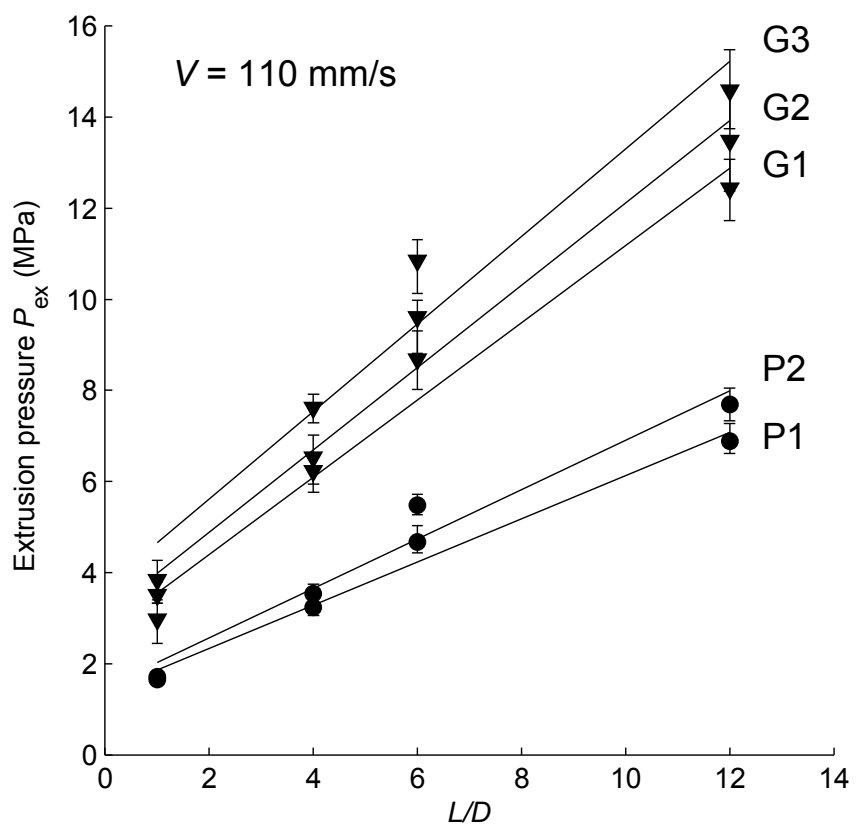

(b)

Figure 4: (a) Extrusion profiles for all pastes with a single-holed die, $D_{0}=11 \mathrm{~mm}, L / D=12$ $\mathrm{mm}$ and $V=110 \mathrm{~mm} / \mathrm{s}$. (b) Average extrusion pressure within the sampling region in (a) for all pastes as a function of $L / D$ at $V=110 \mathrm{~mm} / \mathrm{s}$, with bars indicating the extrusion pressure range in the same region. - symbols are pastes P1, P2, $\mathbf{\nabla}$ symbols are pastes G1, G2 and G3. Solid lines are BB model fits to the data.

For each spheronisation, the entire batch of dried pellets was analysed using a Canty-Vision automated image analysis system (JM Canty Inc., USA). Pellet size and shape data were processed using the software package MATLAB (MathWorks Inc., USA).

\section{Results and discussion}

\subsection{Extrusion characterisation}

Typical extrusion profiles for the five pastes are presented in figure 4a for identical $D, L$ and $V$ values. Every profile contains an initial region of increasing pressure followed by a pseudo-steady state period. The transient data are discarded and an average extrusion pressure is calculated in the sampling region marked in the figure. 
It is evident that the mixing protocol influences the steady state extrusion pressure, with $P_{\text {ex }}$ increasing with increasing $\dot{\gamma}_{\max }$. Figure $4 \mathrm{~b}$ shows this is consistent across a range of die lengths $(L$, non-dimensionalised by the die diameter $D$, a constant).

Analysis of the data indicated that the parameter $\alpha$ in the BB model was unnecessary (equal to zero) for modelling the behaviour seen with each paste, and the exponents $m$ and $n$ were equal to 1 . This reduced the model to equation 3 rather than the more complex equation 2. Physically this can be interpreted as the material being perfectly plastic (as opposed to visco-plastic) under the conditions studied, and the wall slip behaviour being linear in velocity but having a finite wall slip-yield stress ( $c f$. a Coulombic static friction coefficient).

$$
P_{\mathrm{ex}}=2 \sigma_{\mathrm{y}} \ln \frac{D_{0}}{D}+4\left(\tau_{0}+\beta V\right) \frac{L}{D}
$$

The remaining parameters in the $\mathrm{BB}$ model, $\sigma, \tau_{0}$ and $\beta$, were regressed simultaneously to the average extrusion pressure data using the ordinary linear least squares method. The results of this regression are shown in figure 5 .

For $\sigma_{\mathrm{y}}$ and $\tau_{0}$, there is a marked increase (a factor of order two) in value between pastes P1 and P2 (mixed using the planetary mixer alone), and pastes G1 to G3 (prepared using the grinder). The parameter $\beta$ increases similarly albeit to a lesser extent. Within each mixer type there is little correlation of any parameter with $\dot{\gamma}_{\max }$, suggesting that $\dot{\gamma}_{\max }$ as calculated is not the most appropriate characterisation of the effect of mixing.

The root cause of these observations is difficult to ascertain. We hypothesise that the mixing conditions affect the cellulose particle size consistent with the crystallite-gel model of Kleinebudde [15], [16]. The higher shear strain rate of the grinder device would be expected to reduce the MCC crystal size more so than the planetary mixer, binding more water into the gel-network of the paste. The reduction in unbound water would reduce the inter-particle lubrication during flow of the material, increasing both the measured plastic yield strength and reducing lubrication at the extruder walls (which is the primary mechanism for wall-slip in these systems [17]). 


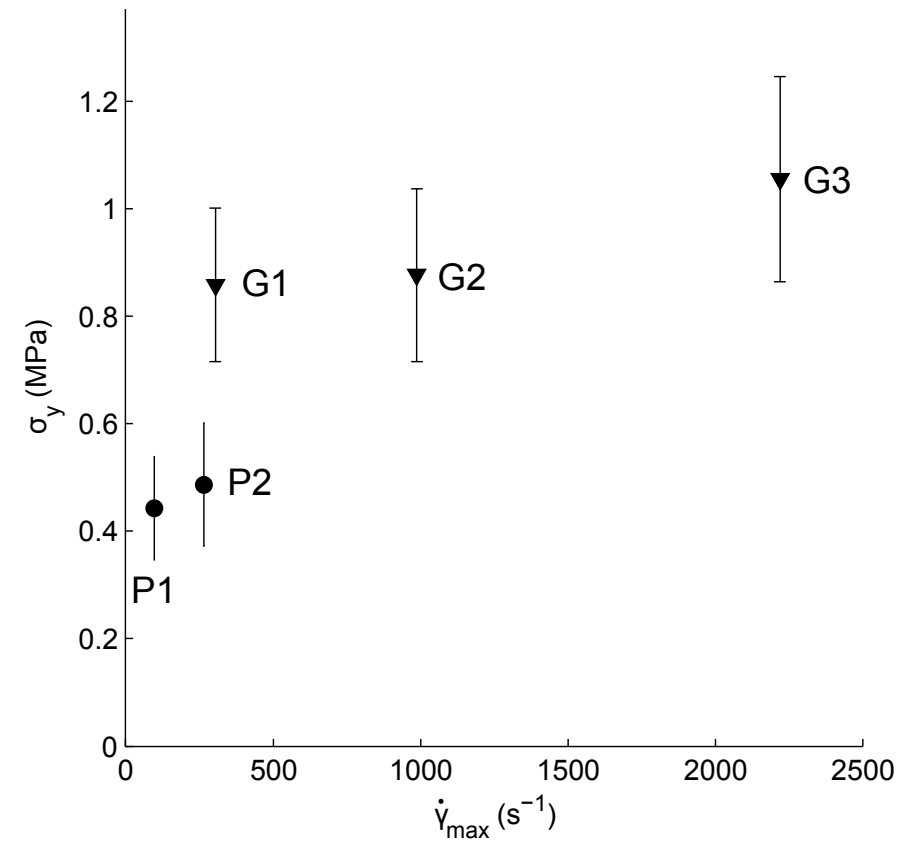

(a)

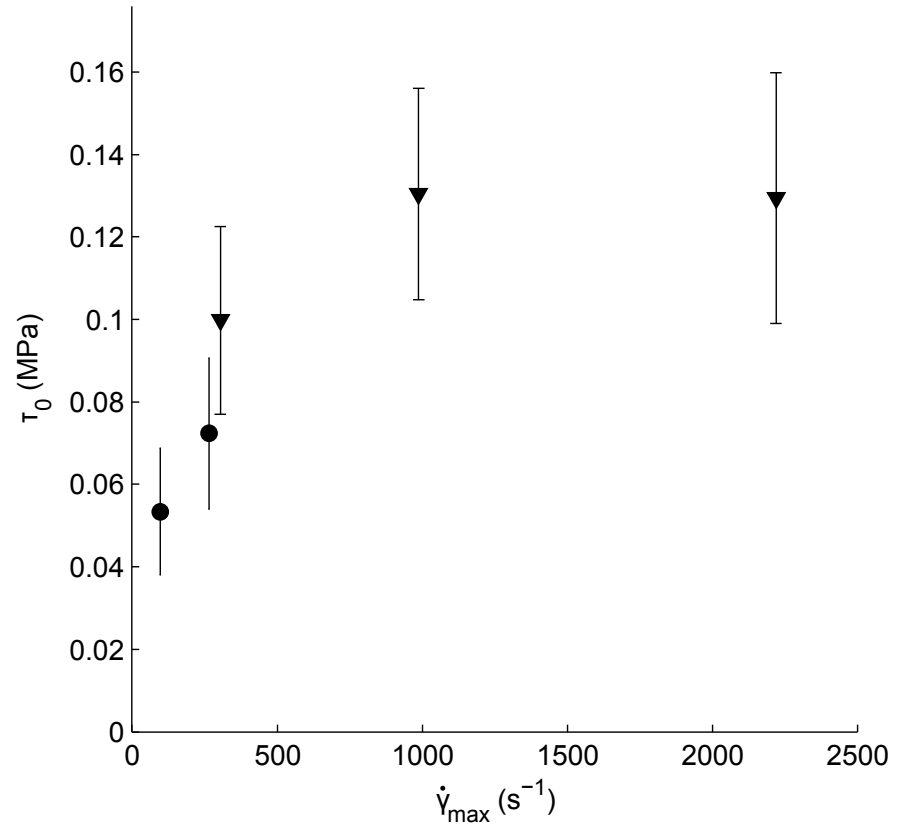

(b)

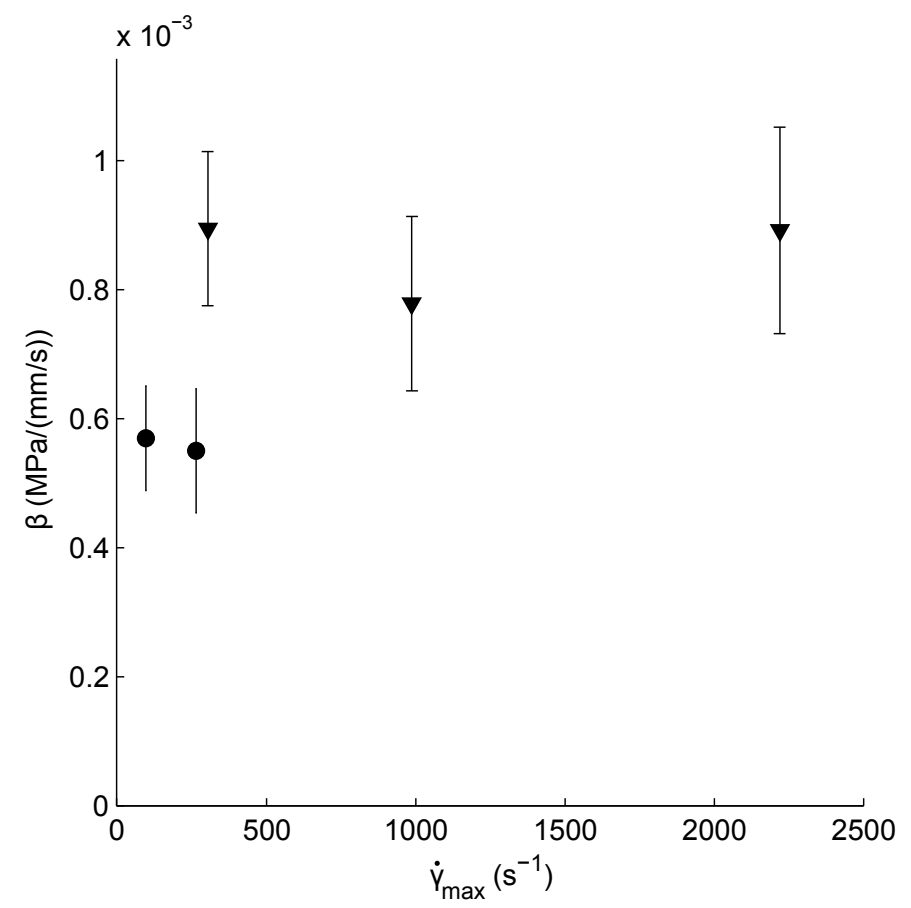

(c)

Figure 5: Benbow-Bridgwater parameters $\sigma_{\mathrm{y}}, \tau_{0}$ and $\beta$ as a function of $\dot{\gamma}_{\text {max }}$. Error bars indicate $95 \%$ confidence intervals for the fitted parameters. - symbols are pastes P1, P2, $\boldsymbol{\nabla}$ symbols are pastes G1, G2 and G3. 
Measurements of the relevant properties of the extruded paste (crystallite size, degree of polymerisation, porosity etc.) which may support this hypothesis lie outside the scope of the current work. Preliminary tests to measure the drying rate of each paste (data not reported), under the assumption that more tightly bound water would leave the MCC matrix at a lower rate, showed no difference between mixing methods. It was, however, observed that the unconfined granules of paste prepared using the grinder were less cohesive than those mixed in the planetary mixer, and were noticeably drier to the touch, despite having the same water content as measured through vacuum drying.

\subsection{Multi-holed extrusion}

Average extrusion pressures for the multi-holed die with each paste are shown in figure 6 . The trend is consistent with that of the single-holed die results; however, there is a general under-prediction of $P_{\mathrm{ex}}$ by the Benbow-Bridgwater model for each $\dot{\gamma}_{\max }$. This is unsurprising as the more complex flow field introduced by the multi-holed die leads to greater redundant work (internal self-shear of the paste) near the yield region, which increases the extrusion pressure. Similar differences between BB model predictions and observations for multi-holed dies were reported by Zhang et al. [10], Rahman et al. [14].

\subsection{Spheronisation performance}

A photograph of typical spheronised MCC pellets can be seen in figure 7 (paste P2 in this instance). As the pellets are near-spherical, the circle equivalent diameter $\left(d_{\mathrm{CE}}\right)$ was used as a representative measure of the size, which was non-dimensionalised by the extrusion die diameter $D$. Consistent with past work with these materials $[10,18,19]$, the mean $d_{\mathrm{CE}} / D$ of the dried pellets was found to tend towards 1 with increasing spheronisation time.

The spheronised pellet size distributions for each paste are plotted in figure 8 alongside the average aspect ratio within bins containing more than 20 pellets. Aspect ratio is defined as the ratio of minor to major axis of the ellipse fitted to the pellet by the particle sizer, and tends towards one with increasing circularity. The bin width chosen was $d_{\mathrm{CE}} / D=0.08$, which corresponds to the approximate 


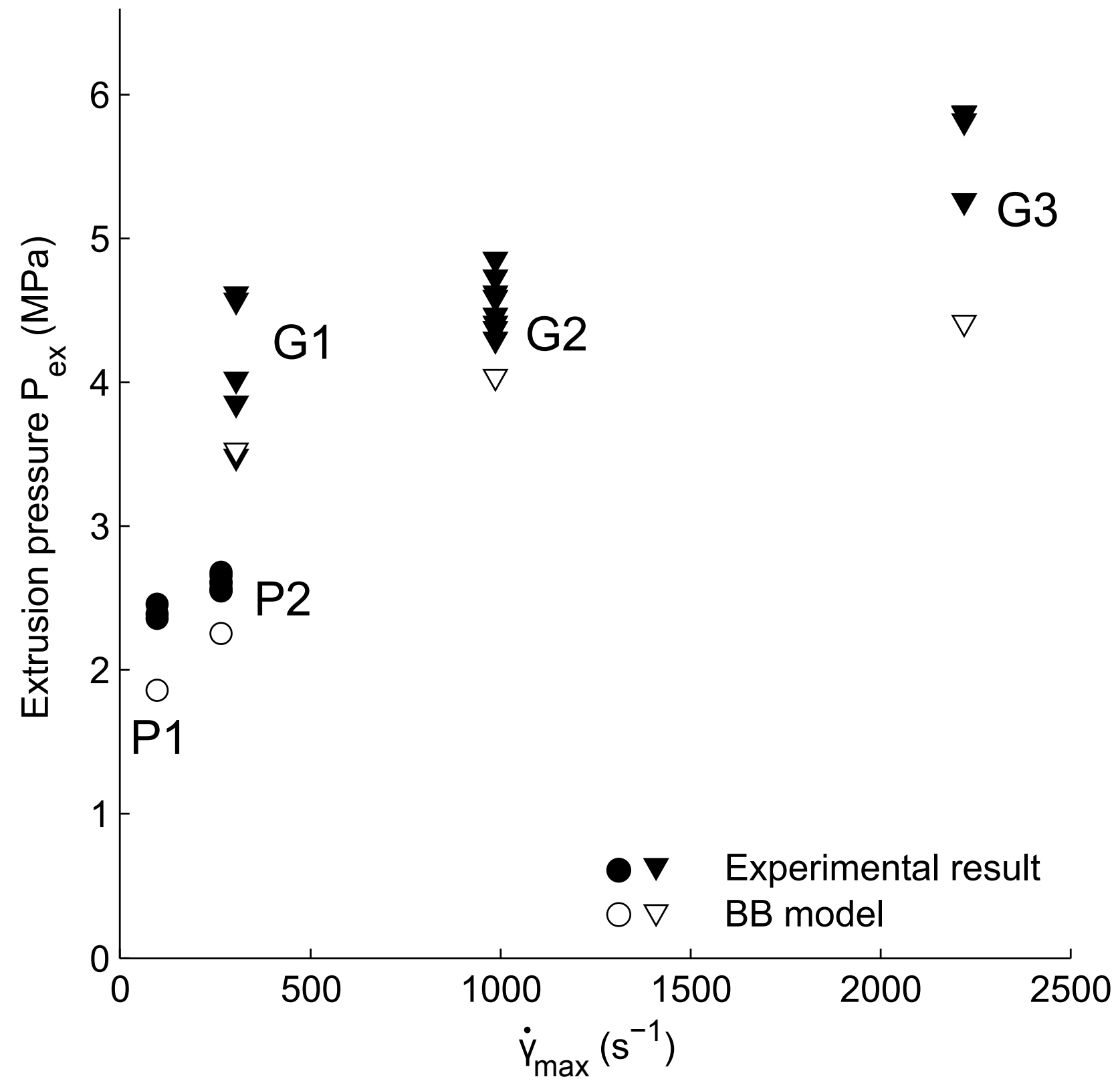

Figure 6: Average extrusion pressure (with repeats) as a function of $\dot{\gamma}_{\max }$ for the multiholed die tests (closed symbols) with Benbow-Bridgwater model predictions for multi-holed die extrusion with each paste (open symbols). $\bullet$ and $\circ$ symbols are pastes $\mathrm{P} 1, \mathrm{P} 2, \nabla$ and $\boldsymbol{\nabla}$ symbols are pastes G1, G2 and G3. 


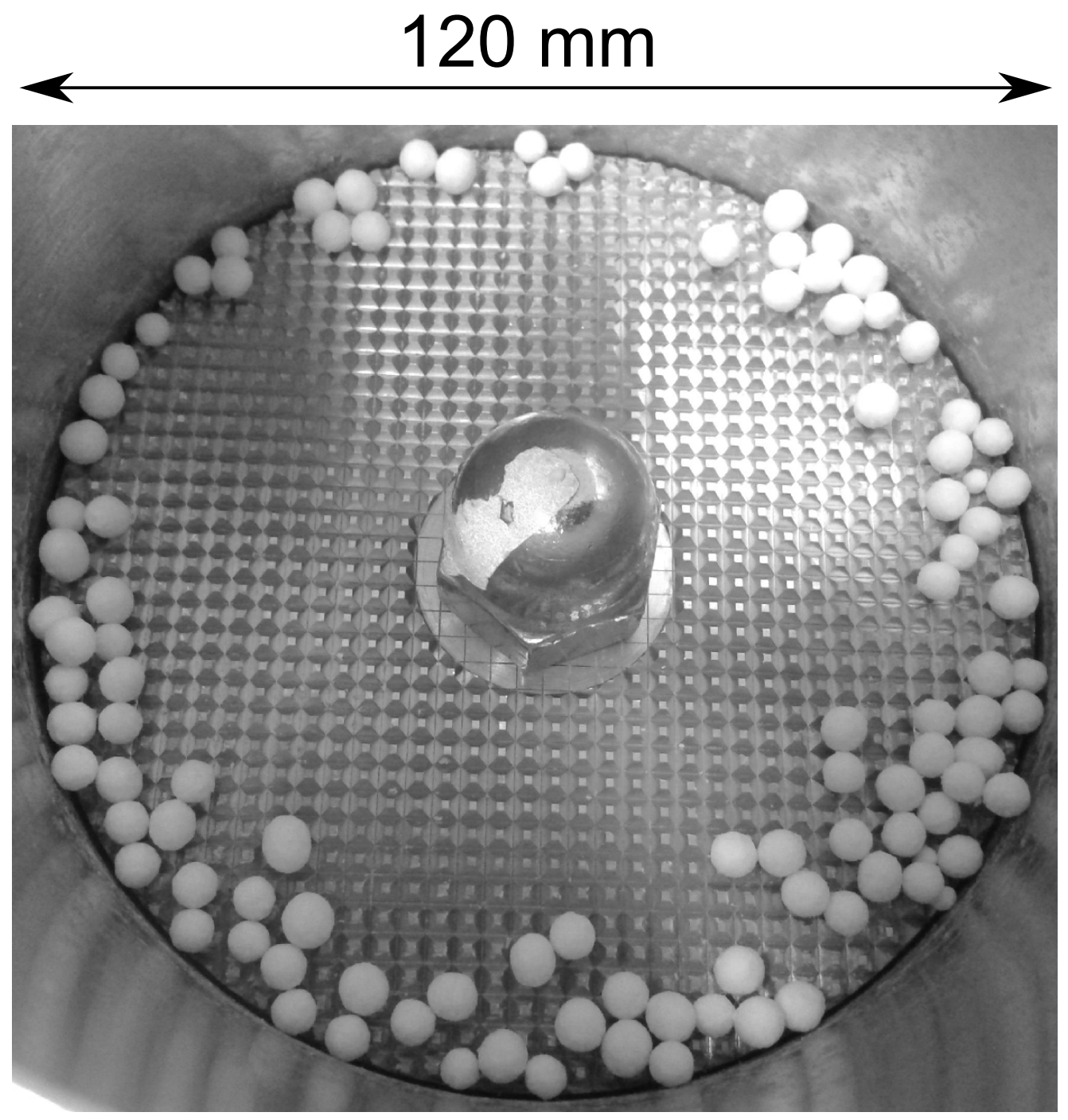

Figure 7: Photograph of pellets in the spheroniser bowl after 8 minutes of spheronisation for paste P2. 
resolution of the particle sizing equipment used. The data are presented as line plots connecting the centres of each bin (rather than a traditional histogram) to allow comparison between pastes at a given spheronisation time.

All spheronisations were performed using extrudates of the same diameter. The initial mass of extrudate spheronised was constant at $55 \mathrm{~g}$. Despite this, there is a marked difference in the distribution of sizes between each mixer type: for all three spheronisation times, the distributions for pastes P1 and P2 are unimodal with positive skew; whereas those for G1 to G3 are initially bimodal and progress towards a single sharp peak with increasing spheronisation time. The bimodal nature of the distribution is indicative of 'fines' production with the grinder-mixed pastes; these fines did not recombine with the larger primary pellets. Pastes P1 and P2 did not show this behaviour. Even after 8 minutes of spheronisation, the pellets generated from paste G3 exhibit a bimodal size distribution.

The aspect ratio data suggest that for all three spheronisation times, both the primary pellet and 'fines' peak are nearly circular in cross section, for all pastes. The horizontal line in each plot (at an aspect ratio of 0.8 ) corresponds to an acceptable degree of sphericity for pharmaceutical pellets for tabletting as noted by Chopra et al. [20]. After 8 minutes of spheronisation, every paste achieves this minimum aspect ratio, although the pastes mixed using the planetary mixer alone are slightly less round (0.9) compared to those processed using the grinder $(0.95)$.

Discarding the data for the pellets below $d_{\mathrm{CE}} / D=0.72$ (in effect digitally sieving the pellets), the statistics for each distribution were calculated and are displayed in figure 9 .

The statistics support the interpretation of the size distribution data shown in figure 8. Increasing spheronisation time has little impact on the main distribution peak location, but does cause a narrowing of the distribution (figure 9b). Increasing $\dot{\gamma}_{\max }$, whether it is an appropriate parameter to classify the mixing or otherwise, reduces the mean pellet size towards $d_{\mathrm{CE}} / D=1$, but has no effect on the spread of the distribution except for paste P1. 


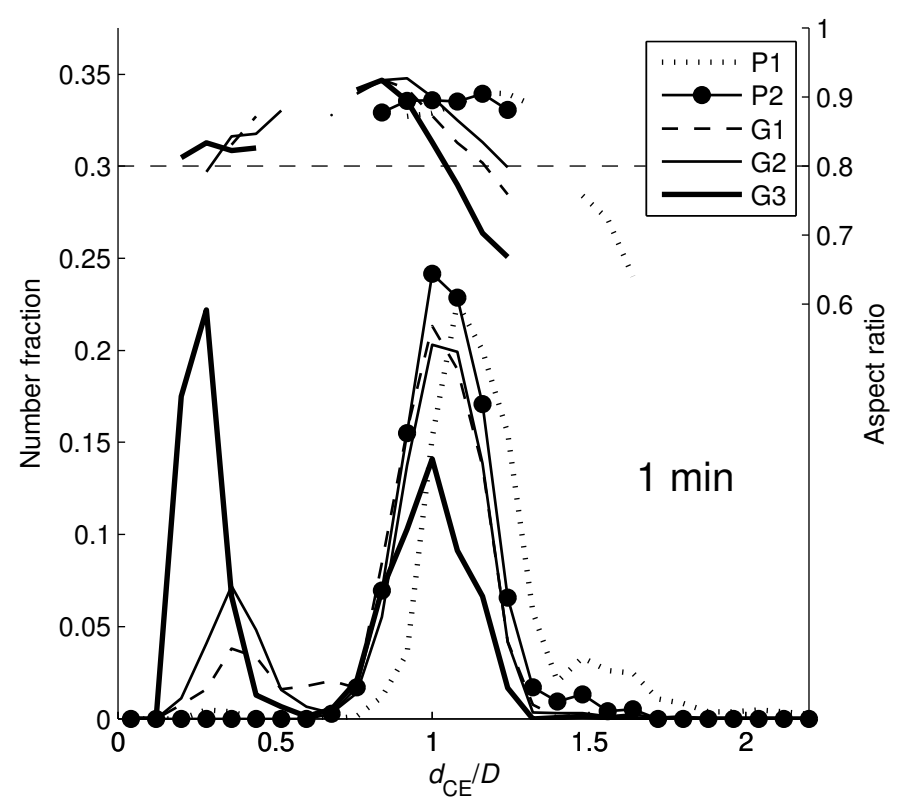

(a)

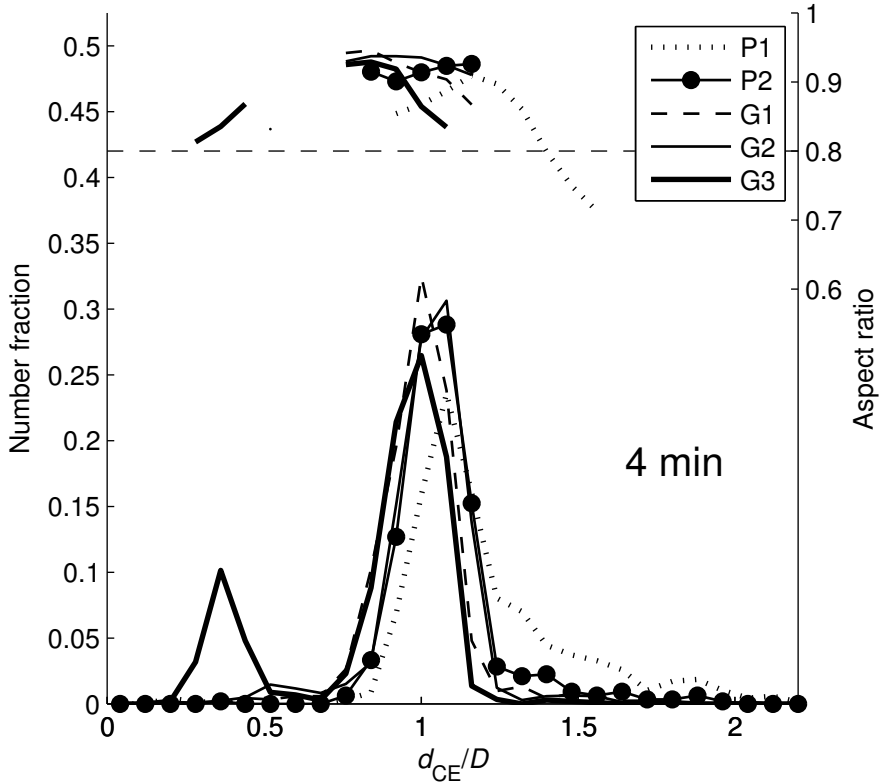

(b)

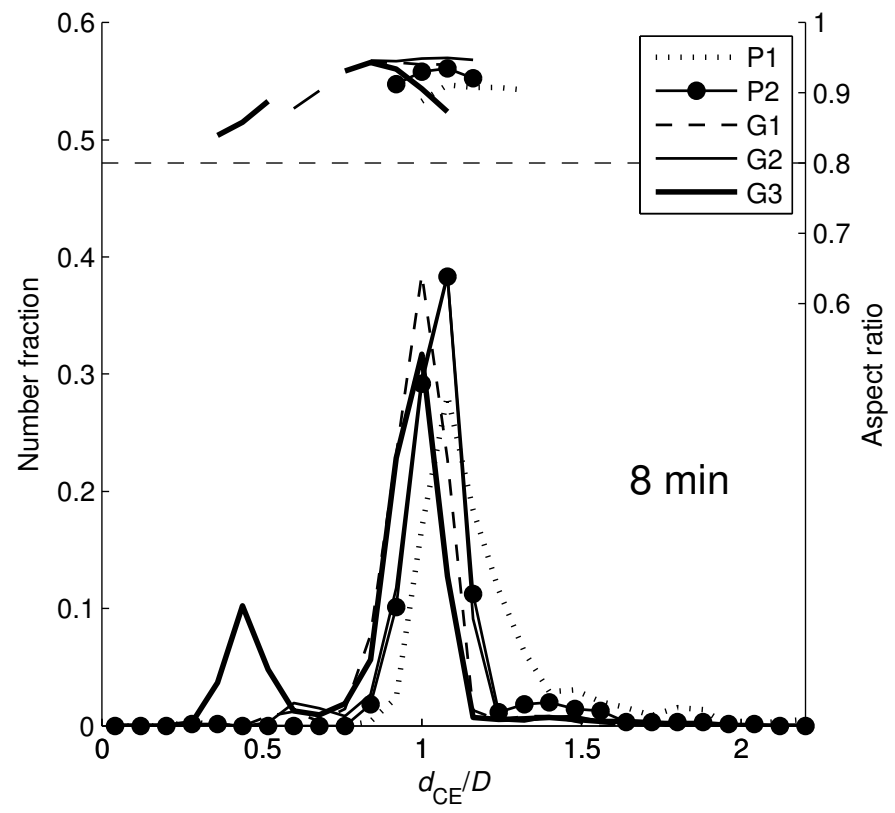

(c)

Figure 8: Scaled pellet size distributions at spheronisation times of (a) 1, (b) 4 and (c) 8 minutes, respectively (lower traces). The upper traces show the average aspect ratio values for bins containing more than 20 pellets. To improve legibility, distributions are shown as lines connecting the centres of the underlying histogram bars with bin size 0.08 . 


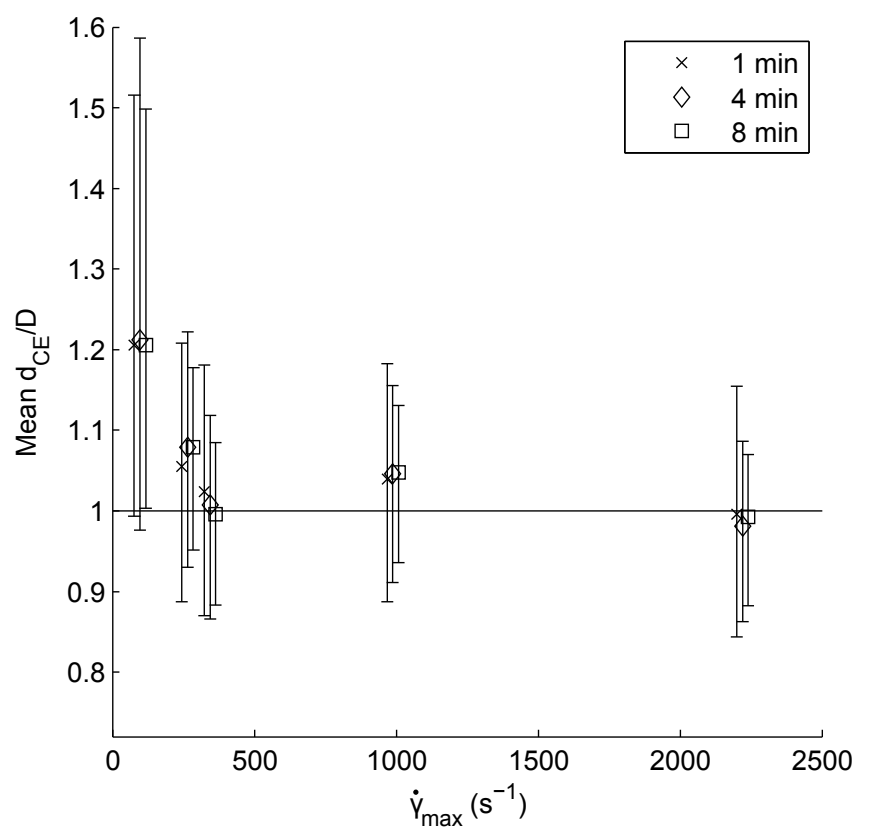

(a)

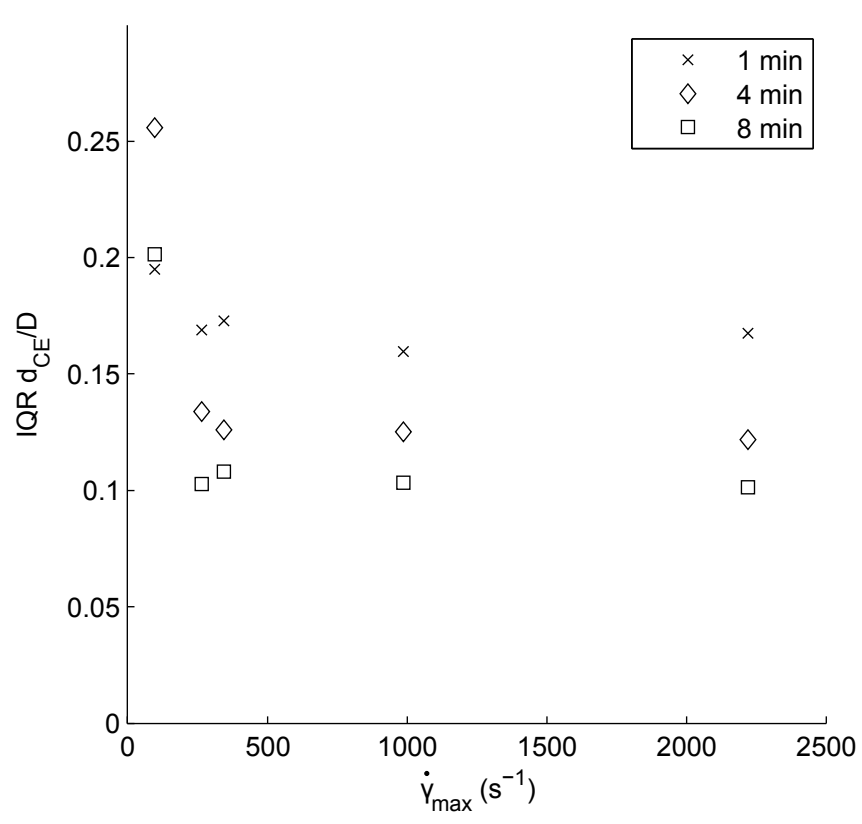

(b)

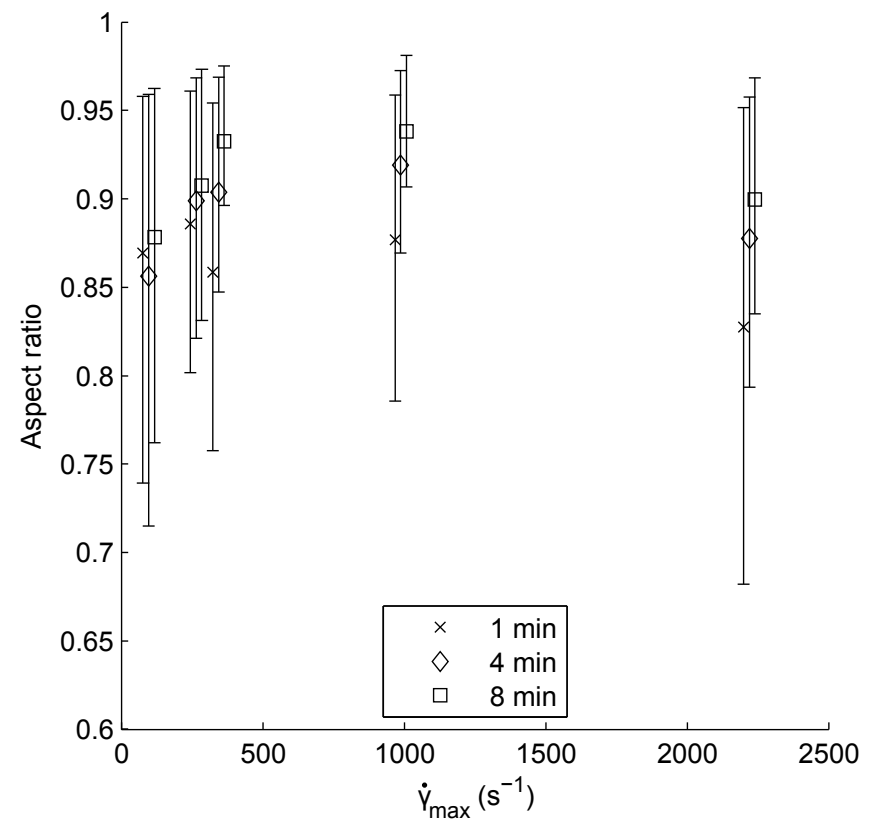

(c)

Figure 9: Distribution statistics for pellet size and shape as a function of spheronisation time, with pellets smaller than $d_{\mathrm{CE}} / D=0.72$ excluded, (a) mean $d_{\mathrm{CE}} / D$, (b) $d_{\mathrm{CE}} / D$ inter quartile range (IQR) and (c) mean aspect ratio. Vertical bars represent 10th and 90th percentiles of the 'sieved' distributions. Points have been offset along the abscissa for clarity. 
Further to this, the aspect ratio of the spheronised pellets (figure 9c) shows overall more rounding with increased spheronisation time (as expected), but also intriguingly pellets of both the lowest and highest $\dot{\gamma}_{\text {max }}$ pastes (P1 and G3) are less round than those at intermediate $\dot{\gamma}_{\text {max }}$ values. This latter result differs from that of Schmidt and Kleinebudde [6], finding that pastes mixed with the planetary mixer had the best overall roundness.

These data are solely observations on the behaviour, as causal links between the paste properties and the pellet size and shape distributions would require tracking the collision behaviour of pellets formed from different pastes. The observations can, however, be linked to the findings in section 3.1, specifically the variation in the plastic yield strength $\sigma_{\mathrm{y}}$.

Both pastes mixed with the planetary mixer (P1 and P2) were found to have a lower $\sigma_{\mathrm{y}}$ than their grinder-mixed counterparts. Collisions of these soft pellets, which are more likely to result in substantial deformation, would explain the observed wide size distribution and decrease in aspect ratio with time.

Paste G3, in contrast, displays persistent bimodality of its size distribution (i.e. a lack of 'fines' recombination) and a lower overall roundness. This behaviour can be attributed to the crystallite-gel model noted in section 3.1 [15]. The higher $\dot{\gamma}_{\max }$ of the grinder would bind the majority of the water in the material into the gel network, reducing the paste deformability and tendency to agglomerate. This lack of agglomeration was noted for the freshly-mixed pastes G1-G3, which were a powder-like in appearance, in contrast to P1 and P2 which formed clusters during the mixing process.

\section{Conclusion}

The observations presented show systematically how varying the preparation method between a low and high shear strain rate mixer affects both the extrusion and spheronisation performance of an $\mathrm{MCC} /$ water paste.

The mixer type, rather than estimated mixer shear strain rate, was found to have the strongest influence on the paste behaviours at both the extrusion and spheronisation stages. Pastes processed with the grinder were more resistant to 
flow, having a higher yield strength and wall shear stress as measured during ram extrusion.

The effect of the mixing stage also manifested itself in the final spheronised pellet size and shape distributions. Pastes mixed using the grinder formed smaller, and in some instances rounder, pellets in contrast to larger pellets with positive size distribution skew from the planetary mixer. Each grinder-mixed paste also formed 'fines' during the early stages of spheronisation, which did not fully recombine with the primary pellets. This is hypothesised to be due to a more tightly bound water/MCC matrix for grinder-mixed pastes consistent with the crystallite-gel model of Kleinebudde [15], reducing the amount of water available for cohesive processes (and consequently increasing macroscopic pellet friability).

These findings, when it is stressed that the only difference between each test is the mixing stage, emphasise a need to consider the mixing in the study or design of an E-S process. Academically, the results suggest that comparison of studies using different mixing methods is not straightforward. While industrially, the scale-up concerns mentioned previously may apply to the extrusion stage, the magnitude of the variation seen at the spheronisation stage may be too small to be of interest. However, these results do suggest potential for optimisation of an E-S process through modification of the mixing conditions.

\section{Acknowledgements}

The micro-crystalline cellulose used in the work presented was kindly supplied by MSD Devlab, Hoddesdon, UK (2011). The authors would also like to acknowledge supporting work by Yuan Lin and Qing Li. Support for MPB is gratefully received from Sandvik Hyperion and Ceratizit GmbH. 
Beater-bowl clearance in planetary mixer .......... (mm)

Blade-plate clearance in grinder $\ldots \ldots \ldots \ldots \ldots \ldots(\mathrm{mm})$

Extrusion die orifice diameter $\ldots \ldots \ldots \ldots \ldots \ldots \ldots(\mathrm{mm})$

Extrusion barrel internal diameter $\ldots . \ldots \ldots \ldots \ldots(\mathrm{mm})$

Circle equivalent diameter of spheronised pellet ....(mm)

Acceleration due to gravity $\ldots \ldots \ldots \ldots \ldots \ldots\left(\mathrm{m} / \mathrm{s}^{2}\right)$

Extrusion die land length $\ldots . \ldots \ldots \ldots \ldots \ldots . . . . .(\mathrm{mm})$

Pellet size $\ldots \ldots \ldots \ldots \ldots \ldots \ldots \ldots \ldots \ldots \ldots \ldots \ldots$. $(\mathrm{m})$

Power-law exponent for non-linear visco-plastic behaviour of extrusion material .......................... (-)

Power-law exponent for wall slip of extrusion material (-)

Extrusion pressure contribution from paste deformation $(\mathrm{MPa})$

Extrusion pressure contribution from wall shear stress in

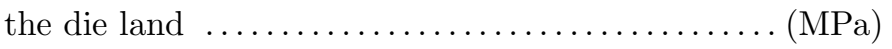

Average 'steady-state' extrusion pressure ........ (MPa)

Local linear velocity of beater $\ldots \ldots \ldots \ldots \ldots \ldots(\mathrm{mm} / \mathrm{s})$

Pellet collision speed $\ldots . \ldots \ldots \ldots \ldots \ldots \ldots \ldots . \ldots(\mathrm{m} / \mathrm{s})$

Extrudate velocity in die land (assuming plug flow) (mm/s)

Local linear velocity of grinder blade passing outermost plate hole ............................. (mm/s) 


\begin{tabular}{|c|c|c|}
\hline 441 & Greek & \\
\hline 442 & $\alpha$ & Velocity coefficient of $\sigma_{\mathrm{y}} \ldots$ \\
\hline 443 & $\beta$ & Velocity coefficient of $\tau_{\mathrm{w}} \ldots \ldots \ldots \ldots\left(\mathrm{MPa} /(\mathrm{mm} / \mathrm{s})^{n}\right)$ \\
\hline 444 & $\rho$ & 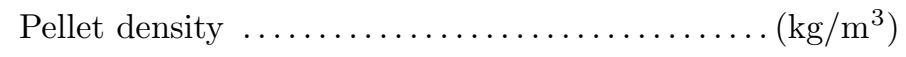 \\
\hline 445 & $\sigma_{0}$ & Benbow-Bridgwater yield stress at zero extrudate velocity \\
\hline 446 & & $(\mathrm{MPa})$ \\
\hline 447 & $\sigma_{\mathrm{y}}$ & Benbow-Bridgwater yield stress $\ldots \ldots \ldots \ldots \ldots . . .(\mathrm{MPa})$ \\
\hline 448 & $\tau_{0}$ & Average wall shear stress in the extrusion die land at zero \\
\hline 449 & & 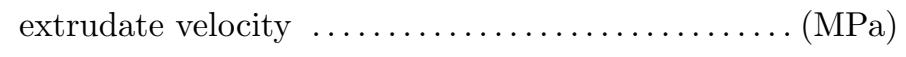 \\
\hline 450 & $\tau_{\mathrm{w}}$ & Average wall shear stress in the extrusion die land (MPa) \\
\hline 451 & $\dot{\gamma}_{\max }$ & Maximum shear strain rate during mixing $\ldots \ldots \ldots\left(\mathrm{s}^{-1}\right)$ \\
\hline 452 & Abbreviations & \\
\hline 453 & API & Active pharmaceutical ingredient \\
\hline 454 & $\mathrm{BB}$ & Benbow-Bridgwater \\
\hline 455 & $\mathrm{E}-\mathrm{S}$ & Extrusion-spheronisation \\
\hline 456 & IQR & Inter-quartile range \\
\hline 457 & $\mathrm{MCC}$ & Micro-crystalline cellulose \\
\hline 458 & PEEK & Polyether ether ketone \\
\hline
\end{tabular}


[1] M. Koester, M. Thommes, Analysis of particle kinematics in spheronisation via particle imaging velocimetry, European Journal of Pharmaceuticals and Biopharmaceuticals 83 (2013) 307-314, doi:10.1016/j.ejpb.2012.08.013.

[2] A. Haring, D. Vetchy, L. Janovska, K. Krejcova, M. Rabiskova, Differences in characteristics of pellets prepared by different pelletization methods, Drug Development and Industrial Pharmacy 34 (3) (2008) 289-296, doi: 10.1080/03639040701655960.

[3] C. Vervaet, L. Baert, J. P. Remon, Extrusion-spheronisation A literature review, International Journal of Pharmaceutics 116 (2) (1995) 131-146, doi:10.1016/0378-5173(94)00311-R.

[4] D. I. Wilson, S. L. Rough, Chapter 3 Extrusion-spheronisation, in: M. H. A.D. Salman, J. Seville (Eds.), Granulation, vol. 11 of Handbook of Powder Technology, Elsevier Science B.V., 189 - 217, doi:10.1016/S01673785(07)80038-8, 2007.

[5] S. Boutell, J. M. Newton, J. R. Bloor, G. Hayes, The influence of liquid binder on the liquid mobility and preparation of spherical granules by the process of extrusion/spheronization., International Journal of Pharmaceutics 238 (1-2) (2002) 61-76, doi:10.1016/S0378-5173(02)00064-9.

[6] C. Schmidt, P. Kleinebudde, Influence of the granulation step on pellets prepared by extrusion/spheronization, Chemical and Pharmaceutical Bulletin 47 (3) (1999) 405-412, doi:10.1248/cpb.47.405.

[7] C. Vervaet, J. P. Remon, Extrusion/spheronisation: influence of the granulation process, European Journal of Pharmaceutical Sciences 4, Supplement 1 (0) (1996) S184 -, doi:10.1016/S0928-0987(97)86564-5.

[8] D. Djuric, B. V. Melkebeke, P. Kleinebudde, J. Remon, C. Vervaet, Comparison of two twin-screw extruders for continuous granulation, European Journal of Pharmaceutics and Biopharmaceutics 71 (1) (2009) 155 - 160, doi:10.1016/j.ejpb.2008.06.033. 
[9] D. Djuric, P. Kleinebudde, Impact of screw elements on continuous granulation with a twin-screw extruder, Journal of Pharmaceutical Sciences 97 (11) (2008) 4934-4942, doi:10.1002/jps.21339.

[10] M. Zhang, S. L. Rough, R. Ward, C. Seiler, D. I. Wilson, A comparison of ram extrusion by single-holed and multi-holed dies for extrusionspheronisation of microcrystalline-based pastes., International Journal of Pharmaceutics 416 (1) (2011) 210-22, doi:10.1016/j.ijpharm.2011.06.043.

[11] M. Zhang, S. Mascia, S. Rough, R. Ward, C. Seiler, D. Wilson, A novel labscale screen extruder for studying extrusion-spheronisation, International Journal of Pharmaceutics 455 (1-2) (2013) 285 - 297, ISSN 0378-5173, doi: 10.1016/j.ijpharm.2013.07.015.

[12] A. K. S. Chesterton, G. D. Moggridge, P. A. Sadd, D. I. Wilson, Modelling of shear rate distribution in two planetary mixtures for studying development of cake batter structure, Journal of Food Engineering 105 (2011) 343-350, doi:10.1016/j.jfoodeng.2011.02.044.

[13] J. Benbow, J. Bridgwater, Paste Flow and Extrusion, Advanced Manufacturing Series, Clarendon Press, ISBN 9780198563389, 1993.

[14] L. Rahman, P. Rowe, A. Cheyne, D. I. Wilson, Ram Extrusion of Potato Starch Dough Through Multi-Holed Dies, Food and Bioproducts Processing 80 (1) (2002) 12 - 19, doi:10.1205/096030802753479061.

[15] P. Kleinebudde, The crystallite-gel-model for microcrystalline cellulose in wet-granulation, extrusion, and spheronization, Pharmaceutical Research 14 (6) (1997) 804-809, ISSN 0724-8741.

[16] P. Kleinebudde, M. Jumaa, F. El Saleh, Influence of degree of polymerization on behavior of cellulose during homogenization and extrusion/spheronization, AAPS PharmSci 2 (3) (2000) 18-27, doi: $10.1208 / \mathrm{ps} 020321$. 
[17] H. A. Barnes, A review of the slip (wall depletion) of polymer solutions, emulsions and particle suspensions in viscometers: its cause, character, and cure, Journal of Non-Newtonian Fluid Mechanics 56 (3) (1995) 221-251, doi:10.1016/0377-0257(94)01282-M.

[18] M. Zhang, D. I. Wilson, R. Ward, C. Seiler, S. L. Rough, A comparison of screen and ram extrusion-spheronisation of simple pharmaceutical pastes based on microcrystalline cellulose, International Journal of Pharmaceutics 456 (2) (2013) 489 - 498, doi: http://dx.doi.org/10.1016/j.ijpharm.2013.08.030.

[19] C. L. S. Lau, Q. Yu, V. Y. Lister, S. L. Rough, D. I. Wilson, M. Zhang, The evolution of pellet size and shape during spheronisation of an extruded microcrystalline cellulose paste, Chemical Engineering Research and Design $\mathrm{x}(\mathrm{x})(2014) \mathrm{xx}-\mathrm{xx}$, doi:10.1016/j.cherd.2014.01.018.

[20] R. Chopra, F. Podczeck, J. M. Newton, G. Alderborn, The influence of pellet shape and film coating on the filling of pellets into hard shell capsules., European Journal of Pharmaceutics and Biopharmaceutics 53 (3) (2002) $327-33$. 

Fig1b

planetary

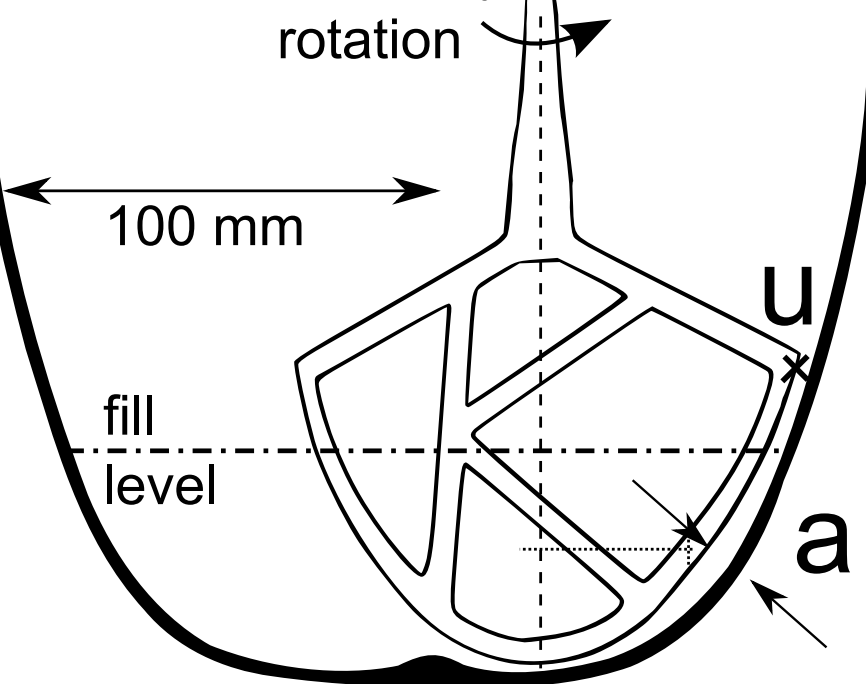




\section{Feeder}

Housing

\section{Auger}

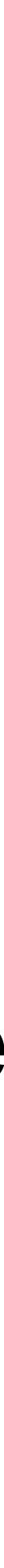




$$
\phi=8 \mathrm{~mm}
$$
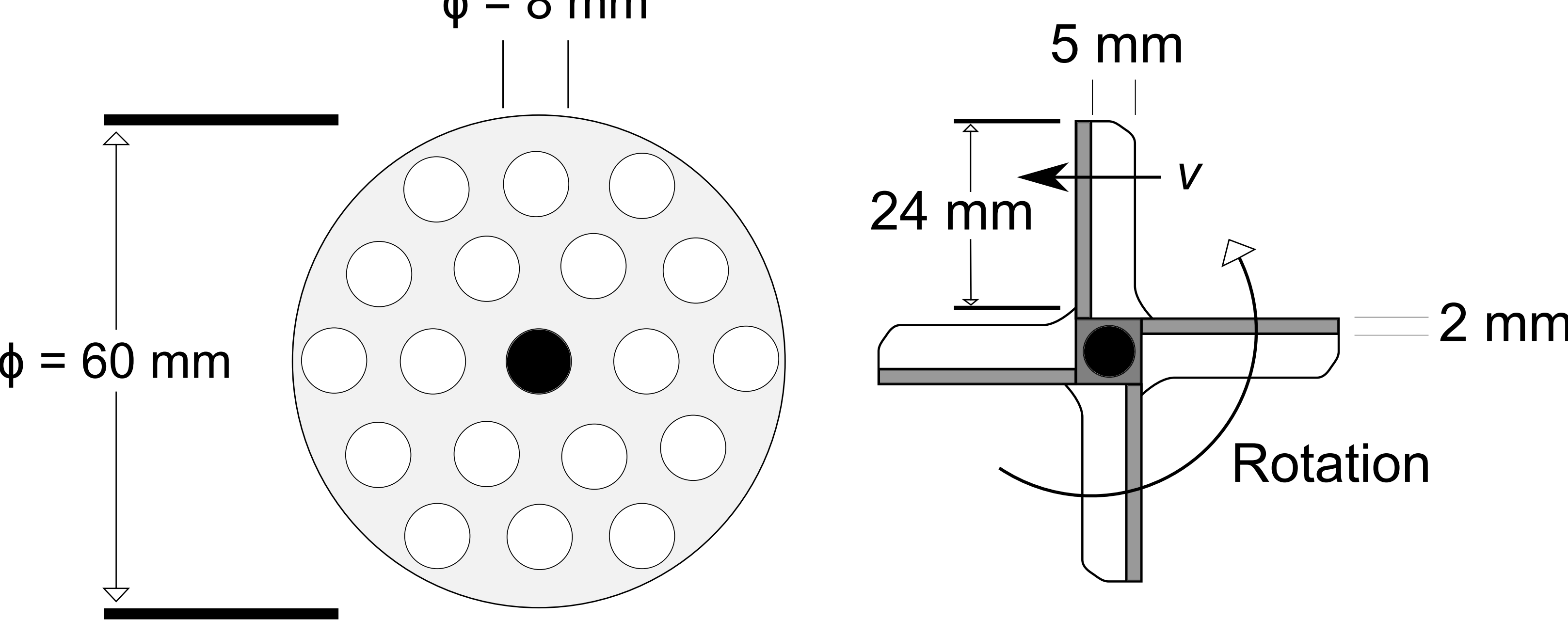

Flow

Top view:

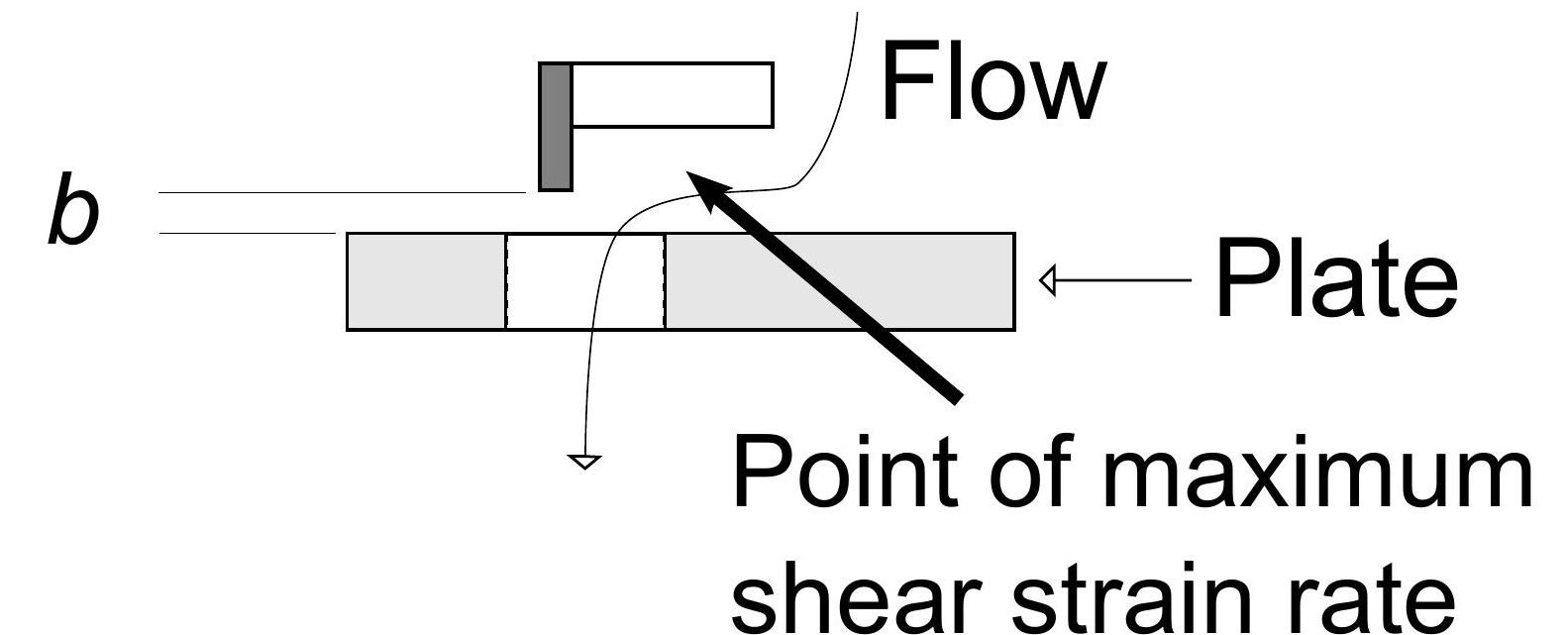



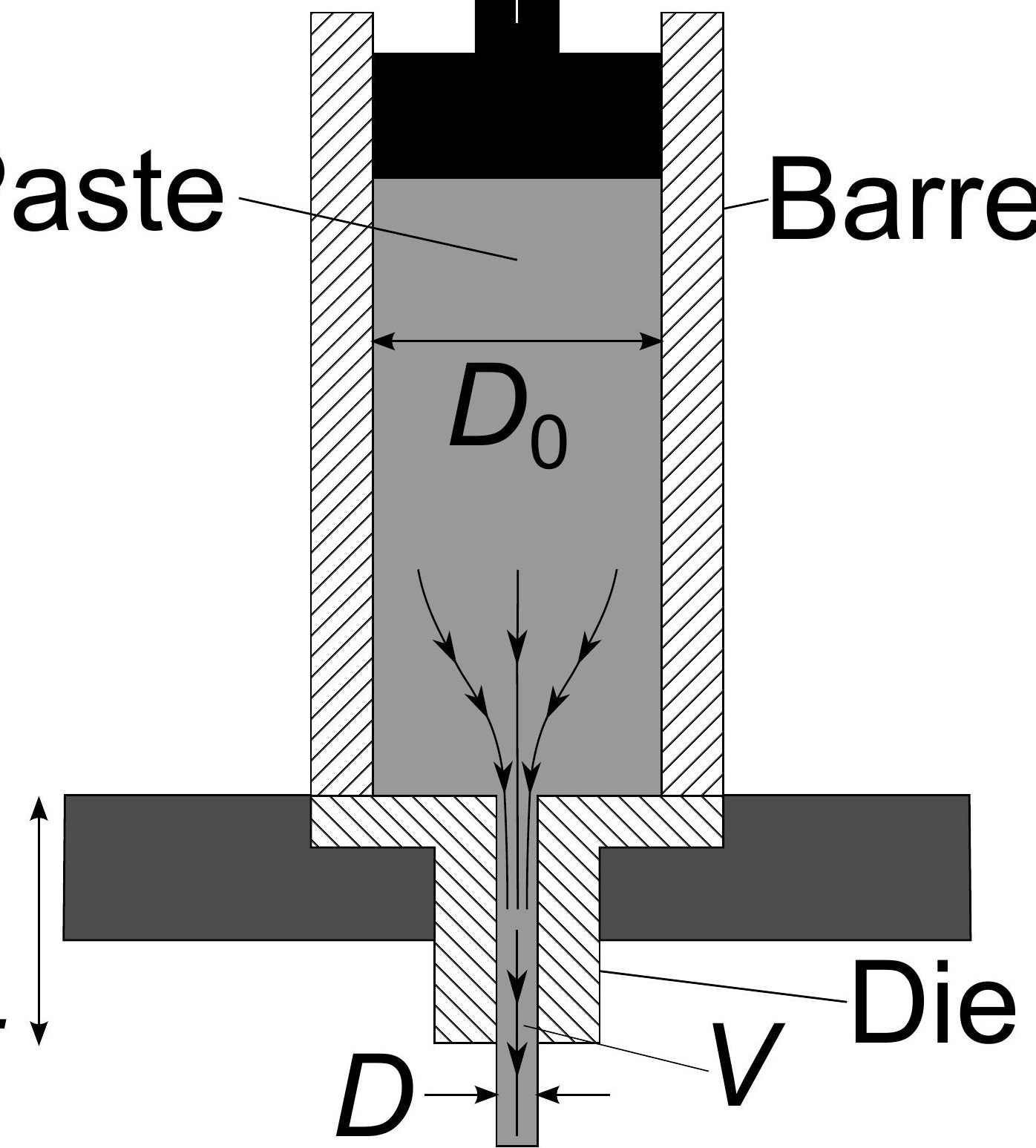

-Barrel
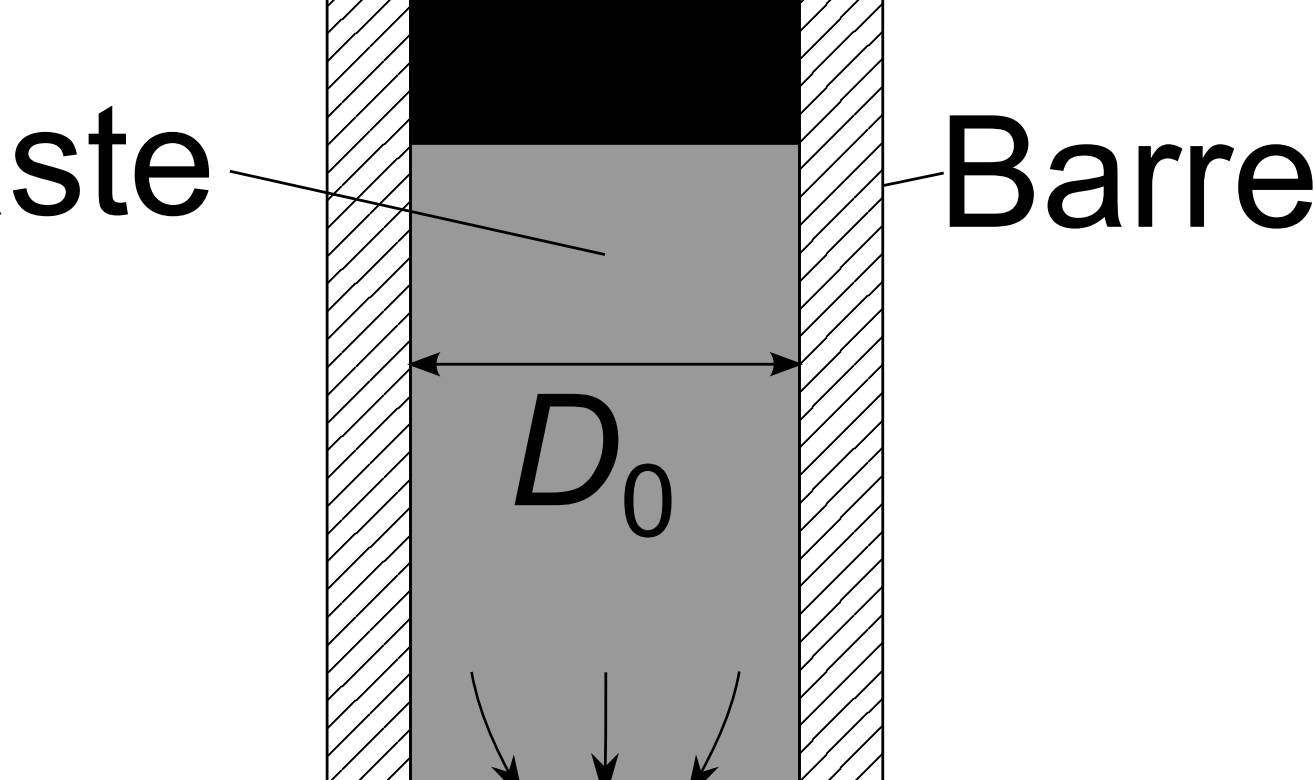

$L$
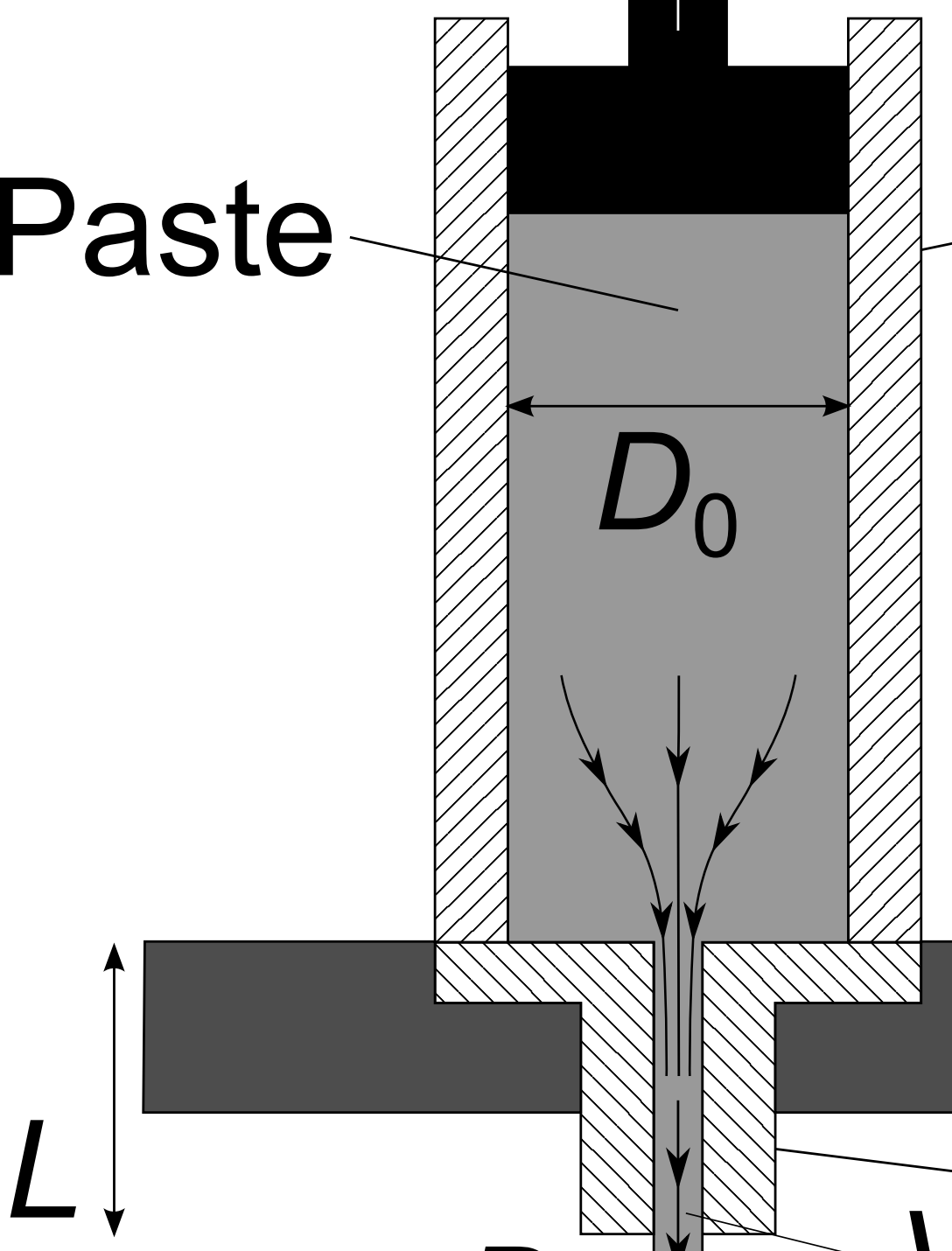
Fig3b

$\phi=2 \mathrm{~mm}$
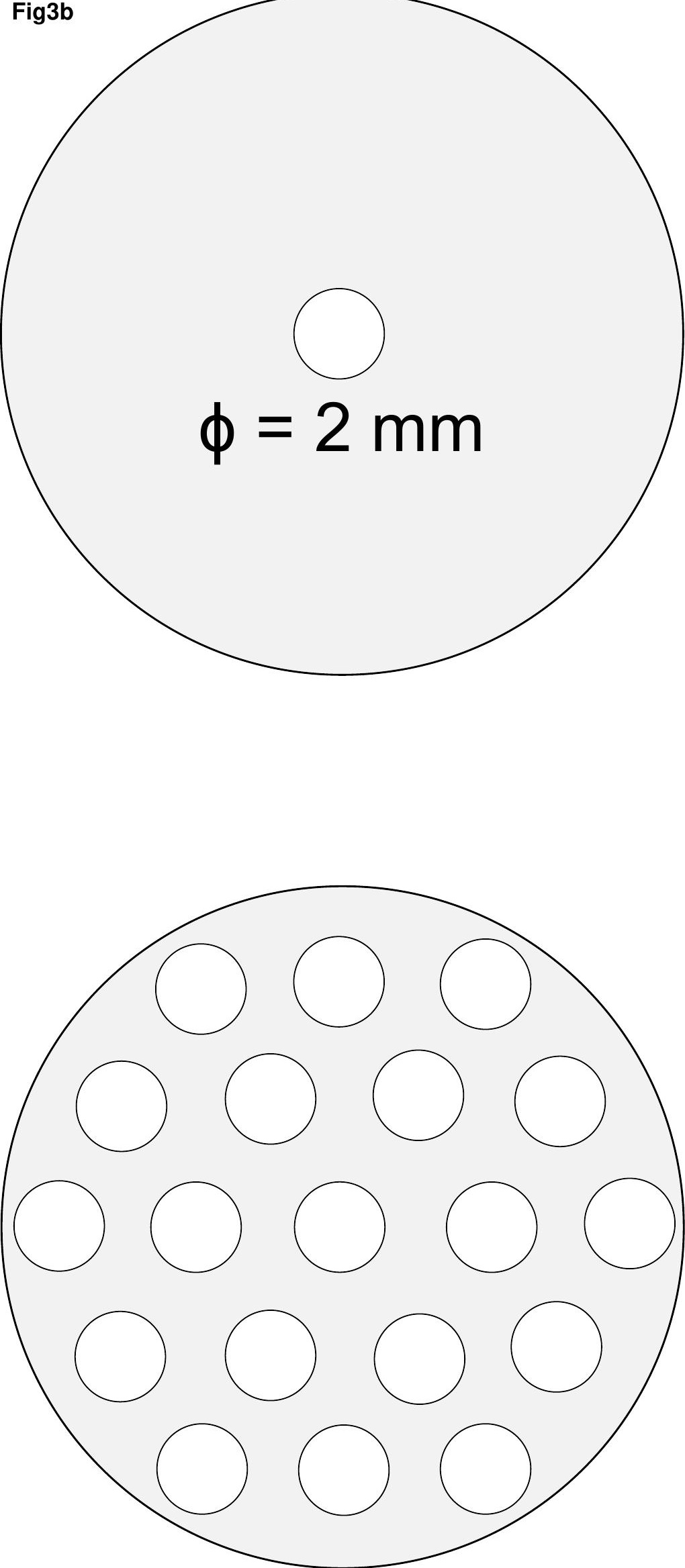


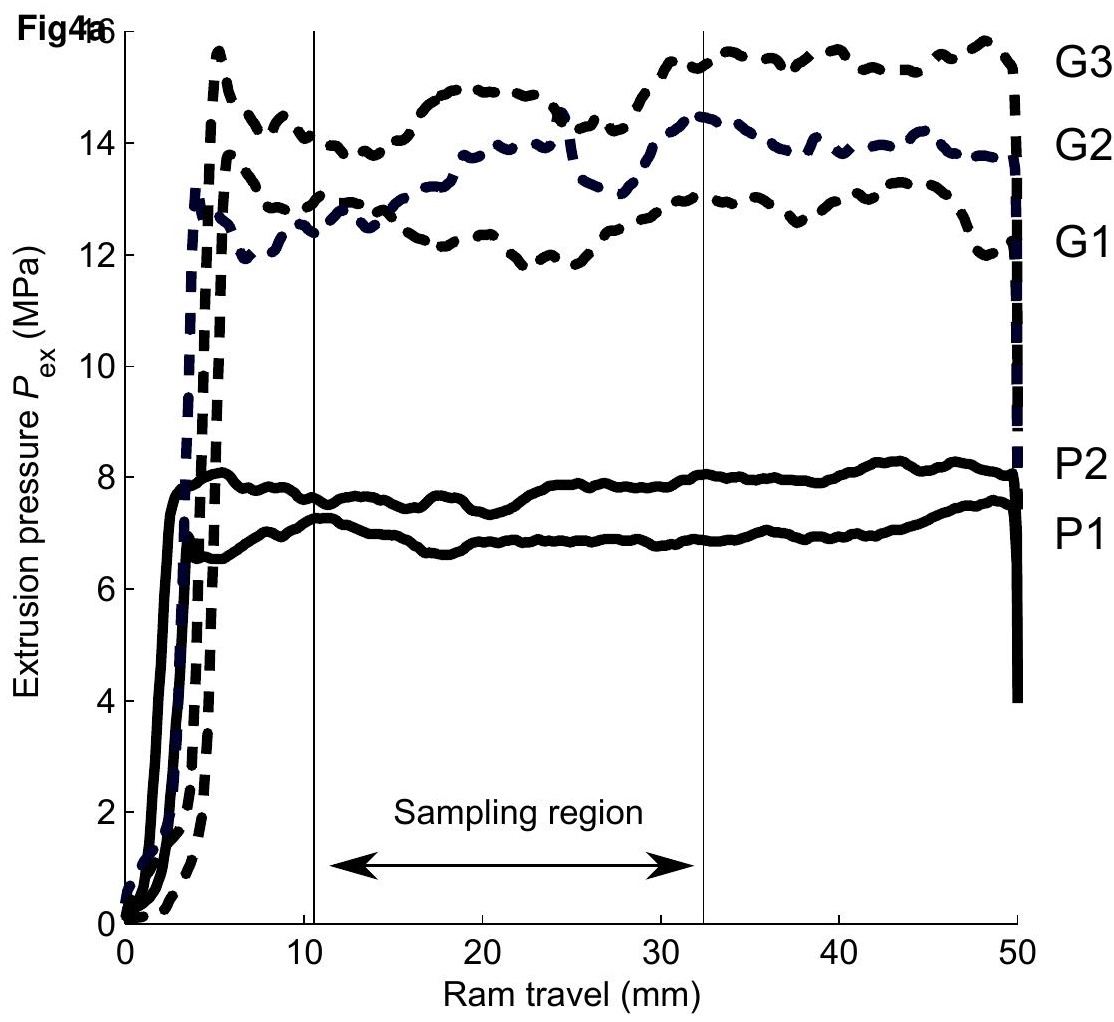




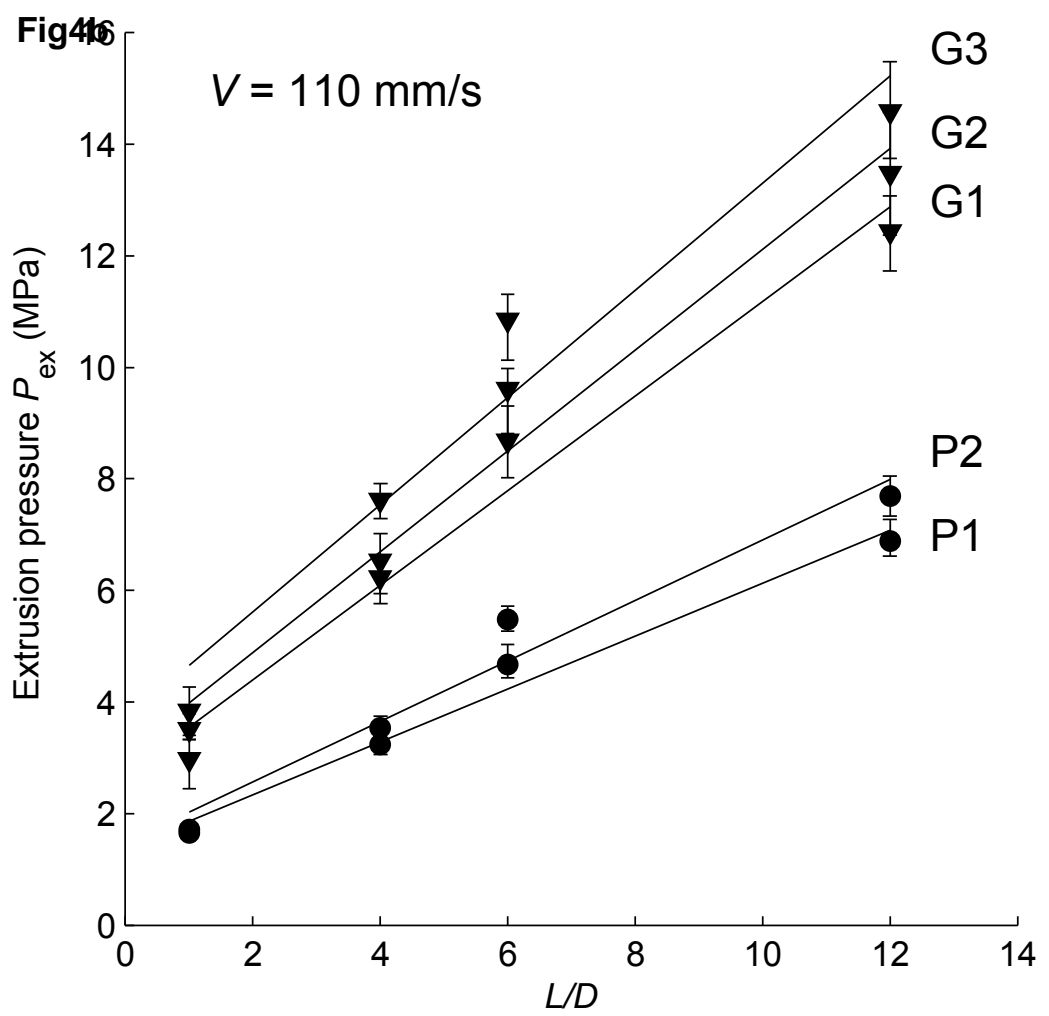




\section{Fig5a}

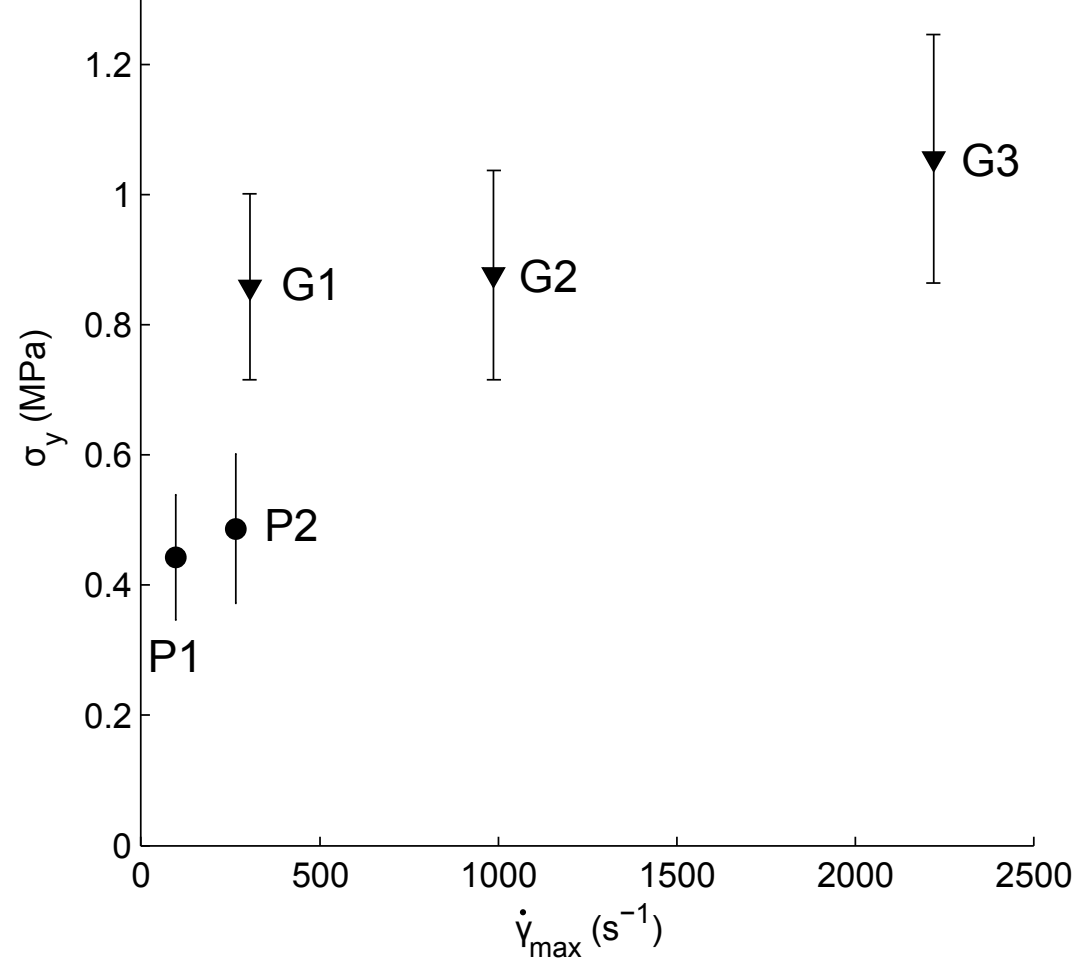




\section{Fig5b}

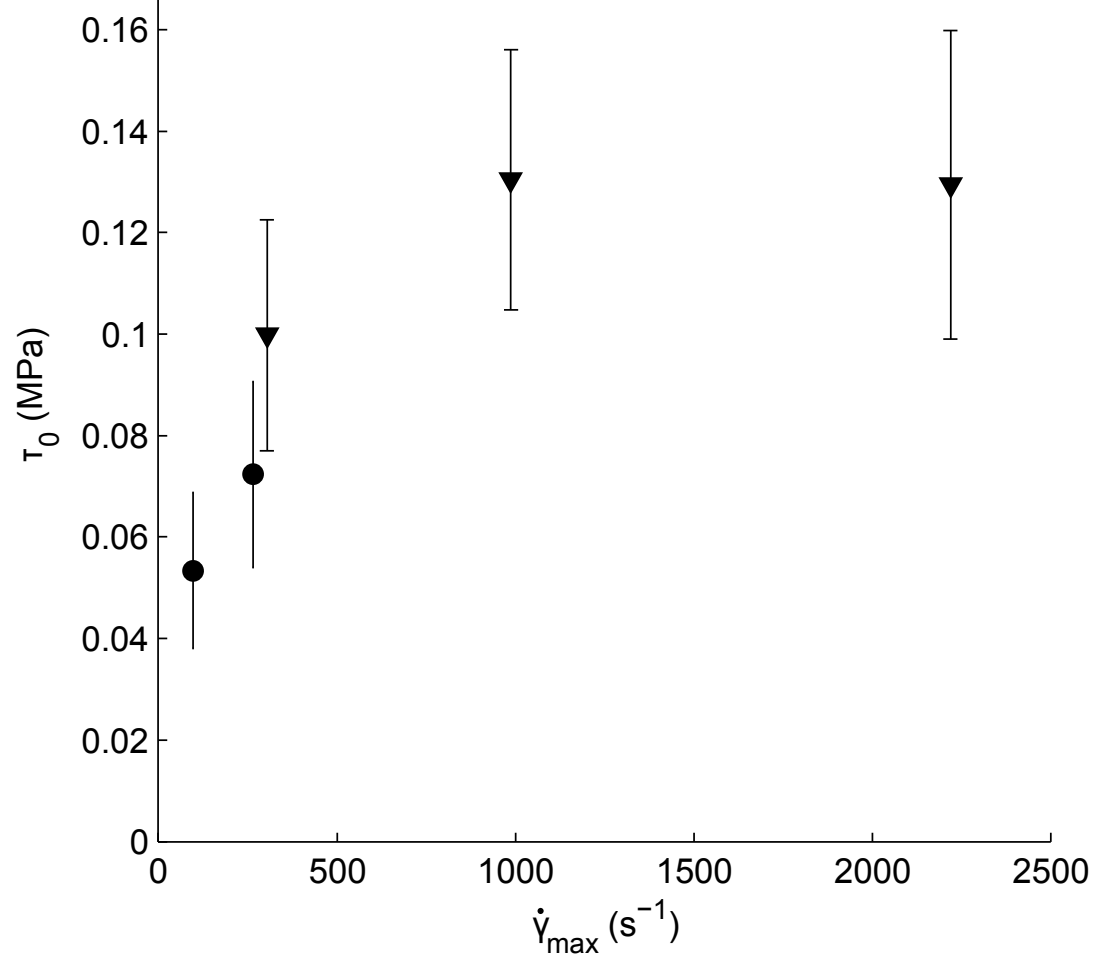


Fig5c $\times 10^{-3}$

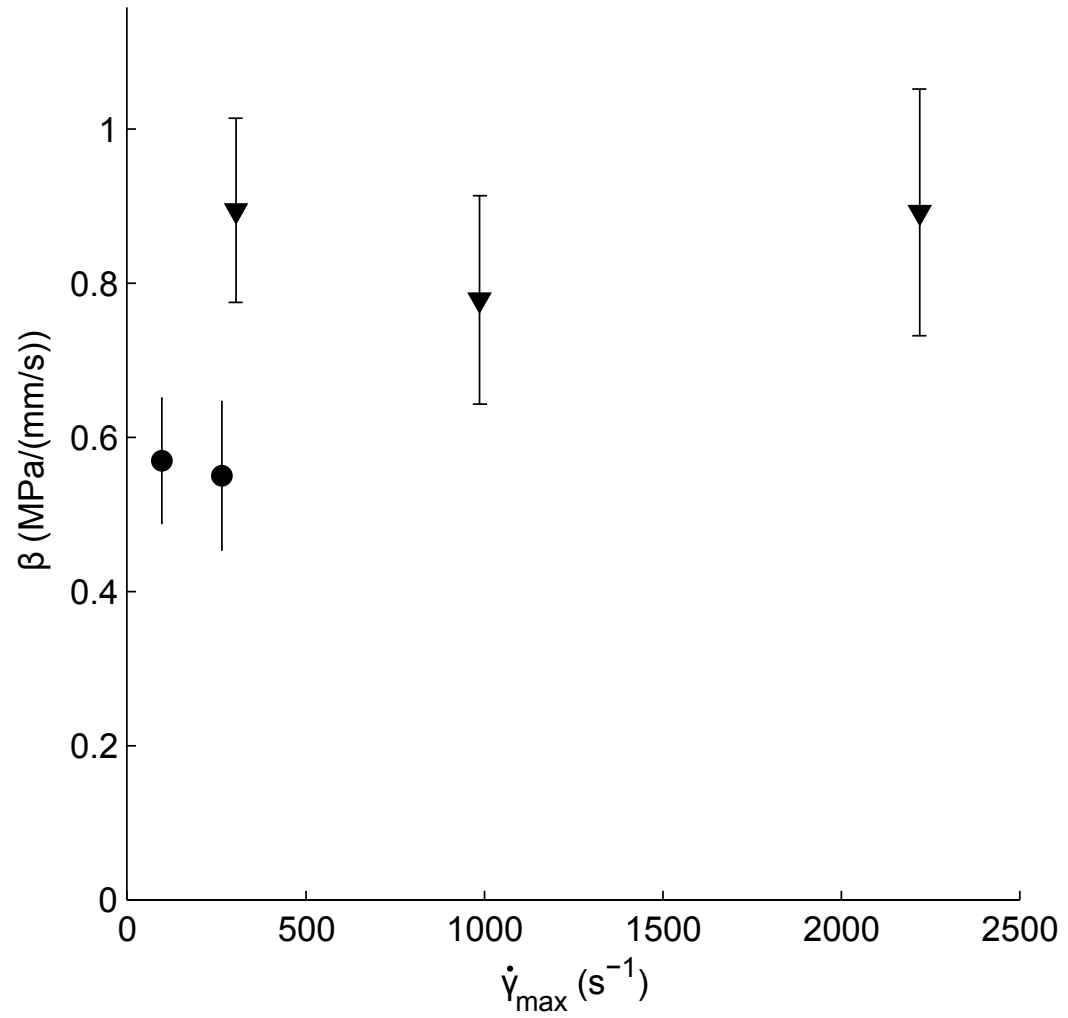


Fig8a

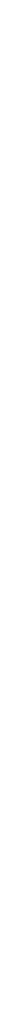




\section{Fig8b}

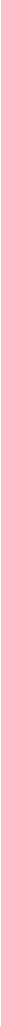




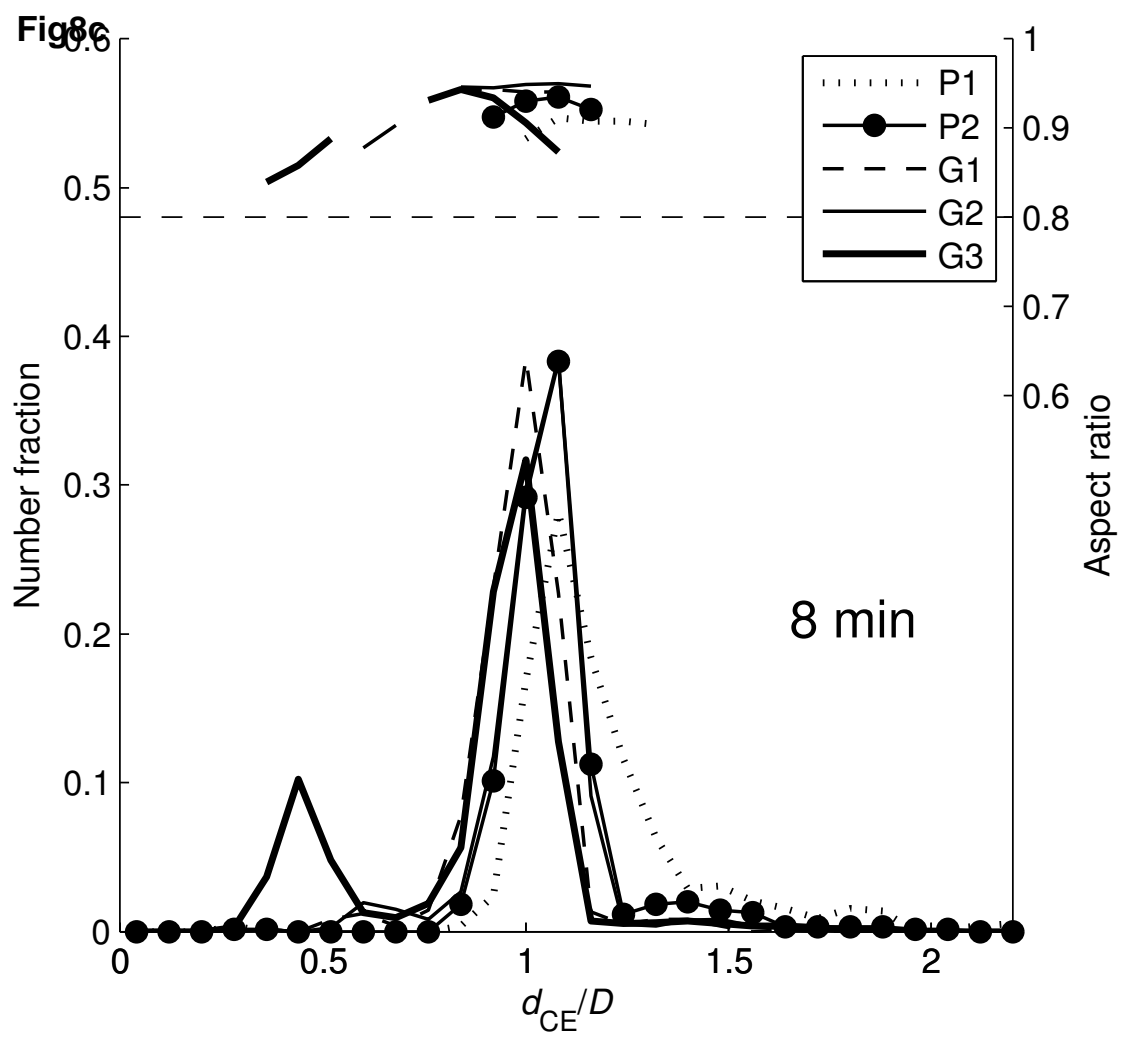


Fig9b

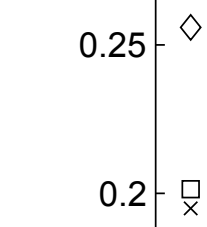

$x^{x}$

$\times$

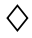

$\diamond$

0

0 $\diamond \diamond$

$0.1-\square^{\square}$

0.05

0.15

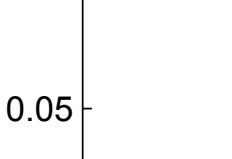

$\square$

ए

\section{$\times \quad 1$ min \\ $\diamond \quad 4$ min \\ ㅁ $8 \mathrm{~min}$}

$\times$




\section{Fig9c $_{1}$}

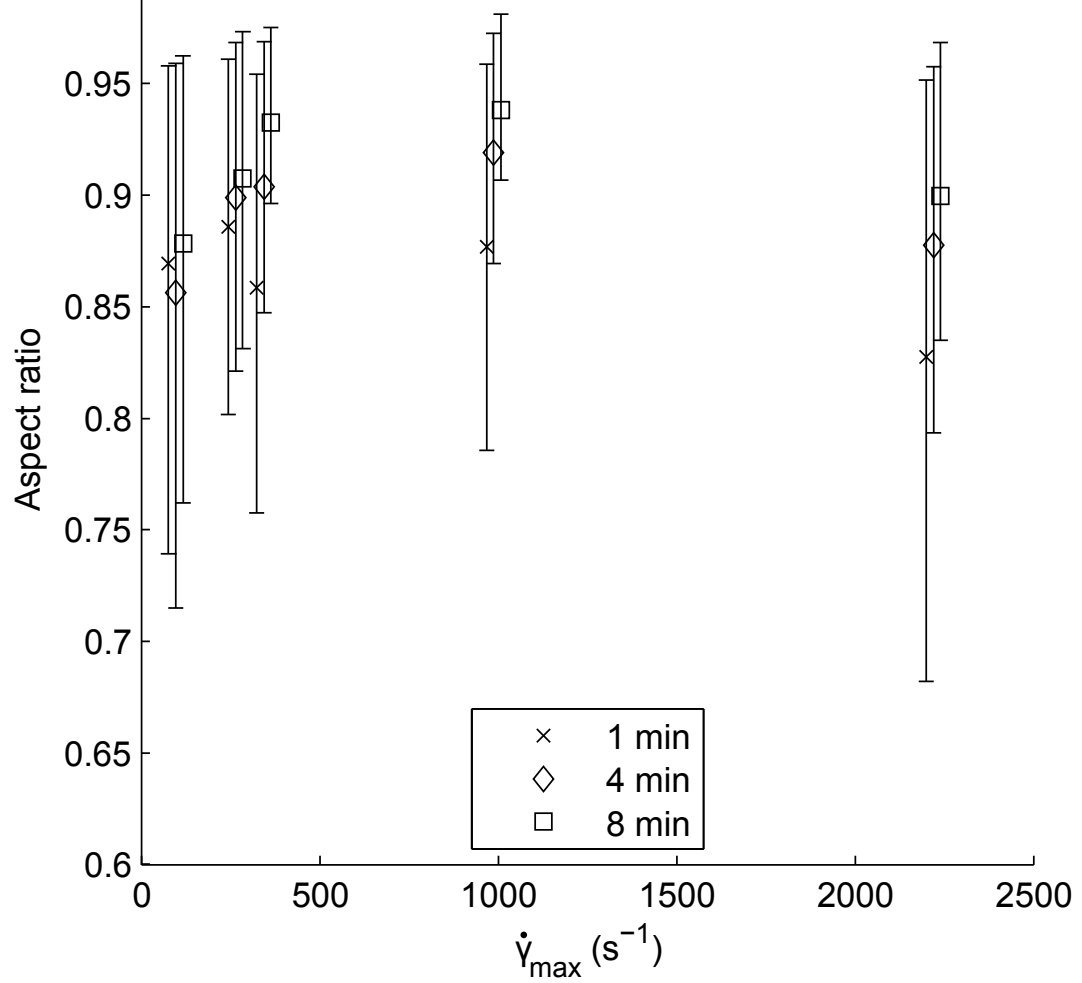


LaTeX Source Files
Click here to download LaTeX Source Files: LatexSourcelJP-D-14-01680R1.zip

LaTeX Source Files
Click here to download LaTeX Source Files: LatexSourcelJP-D-14-01680R1.zip Click here to download LaTeX Source Files: LatexSourcelJP-D-14-01680R1.zip

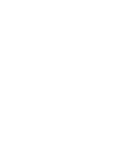

.

(1)

(1)



.

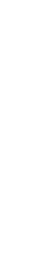

